\title{
High Gene Flow on a Continental Scale in the Polyandrous Kentish Plover Charadrius alexandrinus
}

\section{Citation}

Küpper, Clemens, Scott V. Edwards, András Kosztolányi, Monif Alrashidi, Terry Burke, Philipp Herrmann, Araceli Argüelles-Tico, et al. 2012. "High gene flow on a continental scale in the polyandrous Kentish plover Charadrius alexandrinus." Molecular Ecology 21 (23) (December 25): 5864-5879. doi:10.1111/mec.12064. http://dx.doi.org/10.1111/mec.12064.

\section{Published Version}

doi:10.1111/mec.12064

\section{Permanent link}

http://nrs.harvard.edu/urn-3:HUL.InstRepos:11688780

\section{Terms of Use}

This article was downloaded from Harvard University's DASH repository, and is made available under the terms and conditions applicable to Open Access Policy Articles, as set forth at http:// nrs.harvard.edu/urn-3:HUL.InstRepos:dash.current.terms-of-use\#OAP

\section{Share Your Story}

The Harvard community has made this article openly available.

Please share how this access benefits you. Submit a story.

Accessibility 


\section{High female mediated gene flow on a continental}

2 scale in the polyandrous Kentish Plover Charadrius

3 alexandrinus

4

5 CLEMENS KÜPPER, ${ }^{1,2}$ SCOTT V. EDWARDS ${ }^{1}$, ANDRÁS KOSZTOLÁNYI, ${ }^{3}$ MONIF

6 ALRASHIDI, ${ }^{4}$ TERRY BURKE, ${ }^{2}$ PHILIPP HERRMANN, ${ }^{5}$ ARACELI ARGÜELLES-

7 TICO, ${ }^{5}$ JUAN A. AMAT, ${ }^{6}$ MOHAMED AMEZIAN, ${ }^{7}$ AFONSO ROCHA, ${ }^{8}$ HERMANN

8 HÖTKER, ${ }^{9}$ ANTON IVANOV,${ }^{10}$ JOSEPH CHERNICKO, ${ }^{11}$ and TAMÁS SZÉKELY ${ }^{5}$

$9{ }^{1}$ Museum of Comparative Zoology and Department of Organismic and Evolutionary Biology, Harvard University, Cambridge, MA 02138, USA

${ }^{2}$ NERC Biomolecular Analysis Facility, Department of Animal and Plant Sciences, University of Sheffield, Sheffield S10 2TN, UK

${ }^{3}$ Department of Ethology, Eötvös Loránd University, Pázmány Péter sétány 1/c., H-1117 Budapest, Hungary

${ }^{4}$ Department of Biology, College of Science, University of Hail, PO Box 2440, Hail, Saudi Arabia

${ }^{5}$ Department of Biology and Biochemistry, University of Bath, Bath BA2 7AY, United Kingdom

${ }^{6}$ Department of Wetland Ecology, Estación Biológica de Doñana (EBD-CSIC), Calle Américo Vespucio s/n, 41092 Seville, Spain

${ }^{7}$ Department of Biology, Faculty of Sciences, University of Abdelmalek Essaâdi, PO Box 2121, Tétouan, Morocco

${ }^{8}$ Fundação das Salinas do Samouco, 2890 Alcochete, Portugal

${ }^{9}$ Michael-Otto-Institut im NABU, Goosstroot 1, D-24861 Bergenhusen, Germany

${ }^{10}$ Timiryazev State Biological Museum, Malaya Grusinskaya, 15, Moscow 123242, Russia 
27 Correspondence: Clemens Küpper, Fax +1 617495 5667, E-mail:

28 ckuepper@oeb.harvard.edu

29 
31 Abstract

32 Gene flow promotes genetic homogeneity of species in time and space. Gene flow can be 33 modulated by sex-biased dispersal which links population genetics to mating systems. 34 We investigated the phylogeography of the widely distributed Kentish plover 35 Charadrius alexandrinus. This small shorebird has a large breeding range spanning from Western Europe to Japan, and exhibits an unusually flexible mating system with high female breeding dispersal. We analyzed genetic structure and gene flow using a 427 bp fragment of the mitochondrial (mtDNA) control region, 21 autosomal microsatellite markers and a $\mathrm{Z}$ microsatellite marker in 363 unrelated individuals from 21 locations. We found no structure or isolation-by-distance over the continental range. However, island populations had low genetic diversity, and were moderately differentiated from mainland locations. Genetic differentiation based on autosomal markers was positively correlated with distance between mainland and each island. Comparisons of uniparentally and biparentally inherited markers were consistent with female-biased gene flow. Maternally inherited mtDNA was less structured whereas the Z-chromosomal marker was more structured than autosomal microsatellites. Adult males were more related than females within genetic clusters. Taken together, our results suggest a prominent role for polyandrous females in maintaining genetic homogeneity across large geographic distances.

Keywords: genetic diversity, genetic differentiation, microsatellites, gene flow, sex-biased 51 dispersal 


\section{Introduction}

Investigating the link between ecology and evolution is a central challenge of population biology. Dispersal has a strong influence on gene flow, genetic diversity and population structure which may in turn affect the efficiency of selection and local adaptation (Bohonak 1999; Clobert et al. 2004). However, dispersal is a complex process that is often difficult to assess (Edwards 1994; Okamura \& Freeland 2002). For each individual, the motivation to disperse often depends on age (i.e. natal or breeding dispersal), and may differ between sexes. Sex-biased dispersal has been related to mating systems, resource competition and inbreeding avoidance (Greenwood 1980; Lawson Handley \& Perrin 2007). In socially monogamous species such as many birds, local resource competition among related females is predicted to lead to female-biased dispersal, whereas in polygynous species such as many mammals local mate competition among related males should lead to male dispersal (Clarke et al. 1997; Greenwood 1980; Lawson Handley \& Perrin 2007). A review of mark-recapture studies in birds suggested that dispersal is predominantly female-biased, although many species showed no sex bias and only few studies showed male-biased dispersal (Clarke et al. 1997). However, sex-biased dispersal does not necessarily lead to sex-biased gene flow since it is often not clear whether dispersers are able to successfully breed and contribute to the gene pool at their new location (Prugnolle \& de Meeus 2002).

The results of studies of sex-biased gene flow have challenged simplistic views on associations of sex-biased dispersal with mating systems. In mammals, contrary to the predictions from mating system theory, female dispersal is found in many polygynous species, particularly in primates, whereas male dispersal also occurs in a number of monogamous mammals (Lawson Handley \& Perrin 2007). In birds, few genetic studies have demonstrated female-biased gene flow (e.g. Bouzat \& Johnson 2004; Johnson et al. 2003; Piertney et al. 2000; Rönkä et al. 2008; Rönkä et al. 2012; Wright et al. 2005) and malebiased gene flow is reported from a similarly small number of bird species (e.g. Capparoz et al. 2009; Edwards 1994; Gibbs et al. 2000; Hefti-Gautschi et al. 2009; Liu et al. 2012; MäkiPetäys et al. 2007; Scribner et al. 2001). Importantly, in some birds, male-biased gene flow was even found when recapture data suggested otherwise (Li \& Merilä 2010). 
87 Several approaches have been developed to examine sex-biased dispersal using molecular markers. Studies have compared estimates for population differentiation and migration rates between autosomal microsatellites and sex-specific markers (e.g. markers from nonrecombining chromosomal segments of the Y chromosome or mitochondrial (mt) DNA, e.g. Seielstad et al. 1998; Wright et al. 2005; Lawson-Handley \& Perrin 2007; Douadi et al. 2007). The rationale for the latter approach is that the uniparentally inherited marker is shaped only by the demographic history of the sex carrying the marker. Differences in estimates of population structure or gene flow between uniparentally and biparentally inherited markers may therefore reveal different genetic contributions by the sexes. For species in which females are dispersing and males are philopatric, genetic differentiation is expected to be highest at Y-chromosomal markers, followed by autosomal markers and mtDNA. However, an examination of sex-biased gene flow based only on differences between biparentally and uniparentally inherited markers makes it difficult to disentangle sex-biased dispersal from differences in marker characteristics such as effective population sizes (which for uniparentally inherited markers is $1 / 4$ that of autosomal markers in diploid monogamous systems), mutation rates or selection operating on these markers. Additionally, mtDNA is often subject to bouts of natural selection, making inferences of effective population size from standing levels of genetic diversity within populations challenging (reviewed by Ballard \& Whitlock 2004; Dowling et al. 2008).

To overcome these problems two alternatives have been proposed. First, sex-biased dispersal may be inferred from comparisons of summary statistics between biparentally inherited autosomal markers and biparentally inherited markers such as X- or Z-chromosomal markers that spend more time in one sex than the other one (Carling et al. 2010; Li \& Merilä 2010; Ségurel et al. 2008). X (Z)-chromosomal markers undergo recombination as do autosomal markers, but females (males) carry two thirds of the $\mathrm{X}(\mathrm{Z})$-specific variation. Comparisons between $X(Z)$ markers and autosomal markers to examine sex-specific gene flow provide an improvement over comparisons involving mtDNA since the differences in effective population sizes are less pronounced (the effective population size of $\mathrm{X}(\mathrm{Z})$-chromosomal markers is $3 / 4$ that of autosomal markers). Second, sex-biased dispersal can be inferred by comparing sex-specific summary statistics such as $F_{\mathrm{ST}} / F_{\mathrm{IS}}$-values and relatedness estimates calculated for each sex separately when individuals are sampled after the dispersal event 
119 (Goudet et al. 2002; Prugnolle \& de Meeus 2002). Due to the use of a ratio, this approach largely overcomes the problems caused by different effective population sizes, mutation rates and selection pressures. However, this approach may only detect strong and instantaneous biases because the signal is lost immediately when gene flow is followed by successful reproduction. This is because the offspring will inherit randomly chosen maternal and paternal alleles, thereby destroying any sex-specific pattern of differentiation built up in the previous generation (Prugnolle \& de Meeus 2002).

Here we investigate patterns of genetic diversity, population differentiation and sex-biased gene flow in a small shorebird, the Kentish plover Charadrius alexandrinus. This species has an unusually large geographic range including Northern Africa, Europe and Asia (Cramp \& Simmons 1983). Some populations breed on isolated ocean archipelagos such as Macaronesia (Azores, Canary Islands, Cape Verde Islands, Madeira), and their geographical isolation may reduce exchange of migrants (del Hoyo et al. 1996). Many Kentish plovers are polygamous and have multiple clutches with one parent - usually the female - abandoning the brood to remate whilst the remaining parent provides care for the chicks until the chicks are independent (Amat et al. 1999; Kosztolányi et al. 2009; Lessells 1984; Székely et al. 1999; Székely \& Lessells 1993). The deserting female may then move large distances between different breeding attempts (Székely \& Lessells 1993). This female-biased breeding dispersal may create high sex-biased gene flow between breeding locations.

We sampled thousands of kilometers across the breeding range of the Kentish plover, including eleven mainland and ten island populations. We accomplished three things. First, we compared patterns of genetic diversity between mainland and island populations, and looked for signals of recent population size changes. Second, we investigated the extent of genetic differentiation by including samples from breeding sites across most of its breeding range. Third, we examined whether gene flow is principally driven by dispersing polyandrous females during the breeding season. Because of the problems associated with the various approaches to estimate sex-biased dispersal (Prugnolle \& de Meeus 2002), we tested the hypothesis of female mediated gene flow using three different approaches to compare genetic differentiation and migration rates between mitochondrial DNA, 21 autosomal and a Zchromosomal microsatellite marker. We predicted i) lower genetic differentiation and higher 
migration rates for mtDNA than autosomal markers, ii) stronger genetic differentiation for the Z-chromosomal marker than for autosomal markers, iii) lower genetic differentiation and relatedness among adult females than males.

\section{Material and Methods}

\section{Sampling and molecular analyses}

We obtained DNA samples from 363 presumably unrelated adults or chicks of 21 Kentish plover populations (20 breeding and one wintering population) in Africa and Eurasia (Table 1, Figure 1). Three samples of the closely related snowy plover Charadrius nivosus sampled at Bahía de Ceuta, Mexico $\left(23^{\circ} 54 \mathrm{~N}, 106^{\circ} 57\right.$ W) were included as an outgroup for phylogenetic analyses.

To obtain DNA samples, adult plovers were trapped on the nest during incubation using funnel traps (Székely et al. 2008) or mist nets. Chicks were caught either shortly after hatching in the nest scrape or during opportunistic encounters in the field. We obtained a small blood sample (25-50 $\mu \mathrm{l}$ for adults from brachial vein, $25 \mu 1$ for chicks from tarsal vein) for subsequent genetic analyses. Blood was stored either in Queen's Lysis buffer (Seutin et al. 1991) or absolute ethanol until extraction. All samples were collected between 1997 and 2009 (Table 1).

DNA extraction and amplification of 21 autosomal and one Z-linked microsatellite markers followed methods described in detail in Küpper et al. (2007; 2009). Microsatellite genotypes and sampling locations have been deposited at data dryad accession number XXXX. For mtDNA analyses we used partial control region sequences described in Rheindt et al. (2011) and amplified partial fragments of the D-loop of the control region for samples of ten additional populations using the primers SNPL90 and TS778H (Funk et al. 2007; Wenink et al. 1994) using 20- $\mu$ l Polymerase Chain Reactions (PCRs). PCRs contained approximately 20 ng of DNA and 0.5 units of Taq DNA polymerase (Bioline) in the manufacturer's buffer with a concentration of $1.0 \mu \mathrm{M}$ of each primer, $2.0 \mu \mathrm{M} \mathrm{MgCl}_{2}$ and $0.20 \mathrm{mM}$ of each dNTP. PCRs were carried out on a thermal cycler (MJ Research model PTC DNA engine) using the 
following program: one cycle of $3 \mathrm{~min}$ at $94^{\circ} \mathrm{C}$ followed by 35 cycles of $94^{\circ} \mathrm{C}$ for $30 \mathrm{~s}$, annealing temperature of $55^{\circ} \mathrm{C}$ for $30 \mathrm{~s}, 72^{\circ} \mathrm{C}$ for $30 \mathrm{~s}$, and a final extension cycle of $10 \mathrm{~min}$ at $72^{\circ} \mathrm{C}$. To check for amplification success, we visualized $5 \mu \mathrm{l}$ of each PCR product on a $2 \%$ agarose gel stained with SYBRsafe (Invitrogen).

Products of successful PCRs were precipitated with ethanol and sequenced using Big Dye Terminator Cycle chemistry on ABI 3730 capillary DNA automated sequencers at the Natural Environmental Research Council Biomolecular Analysis Facility (NBAF) at the University of Edinburgh. In total, a 427-bp partial sequence of the D-loop for 245 Kentish plovers and three snowy plovers were available for the subsequent analysis (Table 1). Sequences were aligned using the CLUSTALW algorithm implemented in CodonCode Aligner 2.0.0 beta 7 and deposited in the European Molecular Biology Laboratory database under accession numbers AM941516-AM941551 and HE603647-HE603792.

\section{Statistical analyses}

We used ARLEQUIN version 3.1 (Excoffier et al. 2005) and DNASP version 5 (Librado \& Rozas 2009) to calculate the following mtDNA indices of genetic diversity for each sampling location: number of haplotypes $n_{H T}$, haplotype diversity $h$ and nucleotide diversity $\pi$. For autosomal microsatellites we calculated observed $\left(H_{o}\right)$ and expected heterozygosity $\left(H_{e}\right)$ in ARLEQUIN and allelic richness $A_{\text {rich }}$ using the 'StandArich' package in R (available from http://www.ccmar.ualg.pt/maree/software.php?soft=sarich). $A_{\text {rich }}$ was adjusted to the minimal sample per location among the breeding populations (PST: $n=2$, Table 1). Note that the results did not qualitatively change if we exclude locations where few individuals were sampled (i.e. less than 5 individuals, results not shown). We then compared genetic diversity indices that take into account sample size $\left(\pi, A_{\text {rich }}, H_{o}\right)$ between island and mainland breeding locations using Wilcoxon rank sum tests.

We tested for genetic bottlenecks and demographic changes in two ways. First, for mtDNA we calculated Tajima's $D$ using the program DNASP (Librado \& Rozas 2009). Negative Tajima's $D$ values, if the marker is deemed neutral, may suggest a population expansion after 
a bottleneck whereas positive values may suggest population size decrease. Second, for autosomal microsatellites we used the coalescent method implemented in the program BOTTLENECK (Cornuet \& Luikart 1996) and tested whether observed heterozygosity excess or deficiencies were indicative of a recent bottleneck or population expansion which would follow a bottleneck after colonization. As model for microsatellite evolution we chose the two phased model (TPM) and tested for statistical significance with Wilcoxon signedrank tests.

To test for association of geography with mtDNA we carried out Bayesian phylogenetic analyses. The most appropriate model of sequence evolution was selected in MRMODELTEST 2.2 based on Akaike's information criterion (Akaike 1974; Nylander 2004). The Bayesian analysis was conducted using MRBAYES 3.1 (Ronquist \& Huelsenbeck 2003). We conducted three analyses with different a priori topologies: (1) without constraints of the sample origin ('Unconstrained'), (2) constraining samples from island populations to a monophyletic origin ('Islands Constrained') and, (3) constraining all samples of the same location to monophyletic origins ('All Constrained'). For each topology we conducted the Bayesian analyses using four Markov chains at four different temperatures. Markov chains were sampled every 3000 generations and run for 30 million generations. After completion we checked for chain convergence and removed a burn-in of $25 \%$ ( 7.5 million generations). The most likely topology was chosen based on Bayes factors (Kass \& Raftery 1995; Nylander et al. 2004).

Genetic differentiation among populations was estimated in three ways. First we calculated $\Phi_{\mathrm{ST}}$-values (mtDNA), $F_{\mathrm{ST}}$ and $R_{\mathrm{ST}}$-values (microsatellites) in ARLEQUIN. $R_{\mathrm{ST}}$ is expected to give more accurate differentiation estimates than traditional $F_{\mathrm{ST}}$ if the mutation process of the genetic markers resembles a stepwise process (Balloux \& Lugon-Moulin 2002; Slatkin 1995). Pairwise differentiation coefficients were calculated between all 21 locations. Permutation tests with 1000 randomly generated $\Phi_{\mathrm{ST}} / F_{\mathrm{ST}} / R_{\mathrm{ST}}$-values were used to test the probability of observed values arising by chance. Significance levels were adjusted using qvalues to account for false discovery rates due to multiple testing (Storey 2002). Second, we used factorial correspondence analysis (FCA) to examine genetic differentiation of 
multilocus genotypes using the program GENETIX version 4.05 (Belkhir et al. 1996-2004). FCA is a multidimensional statistical method to visualize data that is superior to principal component analysis when discrete variables such as co-dominant microsatellite loci are involved. Third, we used two Bayesian clustering approaches to examine population differentiation with the autosomal markers. We used STRUCTURE version 2.1 (Pritchard et al. 2000) to estimate the number of clusters $K$ in our data set and to assign individuals based on the admixture model with correlated allele frequencies to one or several clusters. With this approach a proportion of each individual's genome is assigned to each cluster assuming gene flow among populations. We ran ten independent simulations with 500,000 generations following a burn-in of 250,000 for $K$ ranging from 1 (no differentiation) to 21 (maximum divergence). We evaluated the assignment probabilities, log likelihood and $\Delta K$ (Evanno et al. $2005)$ to determine the optimal number of clusters. We then used the program TESS version 2.3.1 (Chen et al. 2007) to assign individuals to clusters and validate the number of clusters estimated with STRUCTURE. In TESS we used the hierarchical mixture model where the prior distribution on cluster labels is determined by a Hidden Gaussian Random Field (CAR model). This approach may provide lower error rates than other clustering methods when low levels of genetic structure are observed (Chen et al. 2007). For each $K$ we ran 50 iterations with 50,000 cycles after discarding a burn-in of 30,000 cycles and chose the best 10 runs $(20 \%)$ according to the lowest Deviance Information Criterion (DIC) values. Average DIC values for each $\mathrm{K}$ were plotted and the most likely $\mathrm{K}$ was determined at the value where DIC values reached a plateau. For both STRUCTURE and TESS we averaged the results of the best ten runs using CLUMPP (Jakobsson \& Rosenberg 2007). Results of the processed runs were visualized with DISTRUCT version 1.1 (Rosenberg 2004).

We tested for isolation-by-distance in two ways. First, we used the Mantel's test implemented in ARLEQUIN to test for a general association of geographic distance with genetic differentiation using all sampled breeding population locations. Second, we carried out a linear regression to test whether the genetic differentiation of island populations was affected by their log-transformed distance to the mainland. We used the largest distance of open water that plovers originating from the mainland needed to cross in order to reach the island breeding locations ('ocean distance'), because we reasoned that plovers would use islands between the mainland and island breeding locations as stepping stones. As measure of 
genetic differentiation we used Rousset's distance $\left(F_{\mathrm{ST}} /\left(1-F_{\mathrm{ST}}\right)\right.$ for microsatellites or $\Phi_{\mathrm{ST}} /$ (1- $\left.\Phi_{\mathrm{ST}}\right)$ for mtDNA, (Rousset 1997). Genetic differentiation was calculated for pairwise comparisons with each island population versus the entire mainland population and we estimated distances with the ruler function in Google Earth version 4.02 (Google 2007). Distances were $\log _{10}$ transformed before the analyses.

To estimate number of migrants ( $4 N_{e} m$ for microsatellites and $2 N_{e} m$ for mtDNA) and the Watterson estimators $\Theta$ we used the coalescent approach implemented in MIGRATE version 3.2.6. We estimated $4 N_{e} m / 2 N e_{f} m$ between and $\Theta$ within all population clusters previously identified through STRUCTURE and TESS. After an initial burn-in of 25,000,000 / 100,000 (mtDNA / autosomal microsatellites) a long chain of 50,000,000 / 1,000,000 trees were sampled of which 50,000/2,000 trees were recorded. Four-chain heating was used with temperatures set to $1,1.2,3$, and 6 to improve tree space sampling. Each run was replicated five times and the Bayesian estimates of the previous run were used as initial estimates of these parameters for the subsequent run and the values of the last chain was recorded. Two independent runs were carried out to confirm that final chains converged at highly similar estimates for modes and $95 \%$ confidence intervals and we report the mean values of the two analyses.

We tested for sex-biased dispersal by comparing genetic estimates of migration and genetic differentiation of biparentally and uniparentally inherited markers in three ways. First, following Wright et al. (2005) we compared migration rates of mtDNA and autosomal microsatellites calculated in MIGRATE. The effective population size $\left(N_{e}\right)$ of maternally inherited mtDNA is only one fourth of biparentally inherited nuclear markers (Avise 2004). If the adult sex ratio of a population is $1: 1,4 N_{e} m$ estimates of nuclear markers divided by four can be compared with $2 N_{e f} m$ rates of mtDNA. Differences are attributed to sex-biased dispersal. Second, we compared pairwise $F_{\mathrm{ST}}$ values derived from the Z-linked microsatellite marker with the values of the 21 autosomal microsatellites for all locations where we sampled at least two males $(\mathrm{n}=20$, PST was excluded). We only included genotypes of males for the calculation of the coefficient of genetic differentiation derived from the Zlinked marker, since females have only a single copy of the $Z$ chromosome. We used a 
Wilcoxon signed-rank test to examine statistical significance of autosomal and Zchromosomal $F_{\mathrm{ST}}$ differences. No difference in genetic differentiation between $\mathrm{Z}$ and autosomal markers would suggest lack of sex-biased gene flow. Stronger differentiation at the $\mathrm{Z}$ marker than the autosomal markers indicates female-biased gene flow whereas lower differentiation suggests male-biased gene flow. Third, we used a randomization method implemented in FSTAT to test whether pairwise $F_{\mathrm{ST}}, F_{\mathrm{IS}}$ and relatedness differ between sexes (Goudet et al. 2002). The rationale for this test is that genetic differentiation and relatedness will differ between sexes if one sex largely stays at the natal site whereas the other sex disperses. For this approach the difference between the genetic indices of differentiation or relatedness of adults from both sexes are calculated and then the sex is randomly assigned to each multilocus genotype of the original population sample keeping the original sex ratio intact. Since the analysis is sensitive to sample sizes and power decreases with small sample sizes we used the clusters previously identified with the Bayesian analyses to define populations and repeated this procedure 1000 times to examine statistical significance (Goudet et al. 2002).

Statistical analyses were conducted in R 2.10.1 (R Development Core Team 2010). Analyses involving the software STRUCTURE, TESS and MIGRATE were carried out on the Odyssey Computing Cluster at Faculty of Arts and Science, Harvard University.

\section{Results}

\section{Genetic diversity and tests for bottlenecks}

The 427 bp fragment of the Kentish plover control region contained 34 (8.0\%) polymorphic sites. Among 237 plovers sampled at breeding locations we found 51 haplotypes (54 haplotypes among 245 samples from all 21 locations). Thirty-three haplotypes were exclusive to plovers from mainland breeding locations, ten haplotypes were exclusively found in plovers from island breeding sites and only eight haplotypes were shared between island and mainland breeding locations. However, the shared haplotypes included the three most frequently observed haplotypes and accounted for more than $50 \%$ of the haplotypes observed in both groups (Islands: 56.5\%, Mainland: 63.2\%). 
336 Genetic diversity measured by microsatellite markers was significantly higher for mainland 337 than island populations (Figure 2, Table 2, $A_{\text {rich }}$ : Wilcoxon-rank-sum-test: $\mathrm{W}=94, P<0.001$, $\mathrm{n}=20 ; H_{o}$ : Wilcoxon-rank-sum-test: $\mathrm{W}=76, P=0.047, \mathrm{n}=20$ ). However, there was no significant difference in genetic diversity between mainland and island breeding locations based on mtDNA ( $\pi$ : Wilcoxon-rank-sum-test: $\mathrm{W}=68, P=0.17, \mathrm{n}=20$ ).

We did not find evidence for population expansion, population reduction or selection in mtDNA. Tajima's $D$ values based on mitochondrial haplotypes and coalescent analyses based on the microsatellites were nonsignificant for all mainland or island sites (Table 2). However, two Atlantic island populations had significant heterozygosity excess in microsatellites, suggesting recent population decline (Wilcoxon signed rank test: STM: $P=$ 0.0001; FUV: $P=0.007)$. The coalescent analysis based on the microsatellite genotypes also revealed a mode shift of the allele frequency distribution for the STM but not the FUV population under the TPM model providing further support for the recent population reduction hypothesis at STM.

\section{Phylogenetic analyses}

Bayesian phylogenetic analyses of the mitochondrial data were carried out with the $G T R+I+G$ model of sequence evolution. The 'Unconstrained' model received the highest support, followed by 'Islands Constrained' $\left(2 \log _{\mathrm{e}}(\mathrm{B} 10)=9.46\right)$ and lastly 'All Constrained' $\left(2 \log _{\mathrm{e}}(\mathrm{B} 10)=11.3\right)$. The 'Unconstrained' model had little association with geography, since Kentish plovers from island and mainland populations were grouped together, branch lengths were short, or support was $\leq 0.95$ (Figure S1). Only five nodes were supported by $\geq 0.95$, and their branches contained samples from one island population (TWB), and four mainland populations from the center of the Kentish plover distribution (Figure S1: ELT; ALW; ALW \& XIN; KUJ). 
Pairwise comparisons for mainland-mainland breeding sites revealed very low (or complete lack of) genetic differentiation across autosomal and sex-specific markers. $R_{\mathrm{ST}}$ values for microsatellite data and the majority of $F_{\mathrm{ST}}$ and $\Phi_{\mathrm{ST}}$ values were low and nonsignificant for mainland-mainland comparisons (Tables S1 and S2). Only mitochondrial $\Phi_{\mathrm{ST}}$ values between one of the locations from the center of the continental distribution (ALW) and the three Iberian locations (SAM, FDP, DON) were significant but the $\Phi_{\mathrm{ST}}$ values were low and we interpret these results rather as stochastic effects of a single marker than biologically meaningful. None of the $F_{\mathrm{ST}}$ values calculated from the Z-linked marker were significant but 13 of the 55 pairwise $F_{\mathrm{ST}}$ values for autosomal markers for mainland comparisons were. However, no autosomal $F_{\mathrm{ST}}$ value was larger than 0.03 . $\Phi_{\mathrm{ST}}$ values ranged from -0.05 to 0.14 $($ mean $=0.02, \mathrm{SE}=0.008), F_{\mathrm{ST}}$ ranged from -0.01 to $0.03($ mean $=0.01, \mathrm{SE}=0.002)$ and $R_{\mathrm{ST}}$ ranged from -0.02 to 0.04 (mean $=0.01, \mathrm{SE}=0.002)$ for mainland sites for which at least 10 individuals were sampled. For breeding sites that were separated by open ocean and for which at least ten individuals were sampled most $\Phi_{\mathrm{ST}}, F_{\mathrm{ST}}$ and $R_{\mathrm{ST}}$ comparisons were highly significant. $\Phi_{\mathrm{ST}}$ values ranged from -0.01 to 0.58 (mean $\left.=0.22, \mathrm{SE}=0.019\right), F_{\mathrm{ST}}$ values ranged from 0.02 to 0.17 (mean $=0.07, \mathrm{SE}=0.001)$ and $R_{\mathrm{ST}}$ ranged from 0 to 0.22 (mean $=$ $0.08, \mathrm{SE}=0.006)$.

\section{Genetic differentiation did not follow an isolation-by-distance model, neither for the full data} set (Mantel tests for autosomal microsatellites: $\mathrm{B}=0.000004, P=0.11 ; \mathrm{Z}$ microsatellite: $\mathrm{B}=$ $0.000005, P=0.19$; mtDNA: $\mathrm{B}=0.000012, P=0.064$ ), nor for the partial data set that included only the mainland locations (Mantel tests for autosomal microsatellites: $P=0.99 ; \mathrm{Z}$ microsatellite: $P=0.73$; mtDNA: $P=0.13$ ). The FCA analysis corroborated the lack of genetic differentiation among mainland sites (Figure 3 ) although only $3.4 \%$ of the genetic variation was described by the two first axes. Multilocus genotypes of plovers from distant geographic locations in Eurasia and Africa clustered together. Similarly, samples from PST, FAR and FUV were only poorly differentiated from the continental cluster whereas most samples from the Cape Verde Archipelago (CVB \& CVM), East Asian Islands (TWB, OKN, JAP) and STM were aggregated into separate clusters. 
400

401

402

403

404

405

406

407

408

409

410

411

412

413

414

415

416

417

418

419

420

421

422

423

Genetic differentiation between island and mainland locations for autosomal microsatellites (but not mtDNA or the Z-linked marker) was predicted by ocean distance between island breeding locations and the mainland (Figure 4, autosomal microsatellites: $\mathrm{B}=0.04, \mathrm{r}^{2}=0.56$, $\mathrm{df}=7, P=0.02 ; \mathrm{Z}$ microsatellite: $\mathrm{B}=0.15, \mathrm{r}^{2}=0.23, \mathrm{df}=7, P=0.19 ;$ mtDNA: $\mathrm{B}=0.17, \mathrm{r}^{2}$ $=0.08, \mathrm{df}=7, P=0.46)$.

The two Bayesian analyses for cluster assignment suggested $K=5$ as the most likely number of population clusters. Both analyses consistently flagged three separate clusters (Figure 1): the Azores (STM), Cape Verde (CVB \& CVM) and East Asian Islands (TWB, OKN \& JAP). The wintering population (TWW) was intermediate between the Eastern Asian cluster and continental Eurasian Kentish plovers; a number of individuals had largely continental genotypes suggesting that Kentish plovers from the mainland overwinter in Taiwan. There was disagreement about assignment to the remaining clusters between TESS and STRUCTURE. Results of STRUCTURE suggested two additional clusters: one for breeders from the Canary Islands (FUV) and one for the breeders from Farasan Islands (FAR) with the genomes of mainland Kentish plovers split about equally between these two clusters (Figure 1). The genotypes of the two samples from PST were split between the East Asian and the FUV cluster. Results of TESS suggested one cluster for the mainland Kentish plovers, and assigned the majority of the genotypes of the FUV, PST and FAR plovers to this cluster. However, a significant portion of the genomes ( 0.19 and 0.12 , respectively) of the FUV and FAR plovers were attributed to a joint fifth cluster. For FUV and FAR plovers other significant portions of the genomes were assigned to the CVB/CVM and STM clusters. In TESS runs with higher $K$ values assigned these parts of the FUV and FAR plover genomes to different clusters although the largest part of their genomes was still assigned to the mainland cluster.

\section{Migration}

Because of the uncertain assignment of FAR and FUV breeders, we calculated migration rates assuming six genetic clusters: 1) STM, 2) CVB \& CVM, 3) FUV, 4) Mainland, 5) FAR and 6) TWB, OKN \& JAP. The two samples of breeders from PST were excluded from the 
migration analysis. Results of the two independent runs were consistent and very similar indicating that the runs had converged.

The results of the coalescent analysis showed that island population clusters exchanged few migrants (Table 3). However, island population exchanged migrants with the mainland cluster. MtDNA and microsatellites suggested unequal gene flow with more plovers tending to migrate from islands to the mainland than from mainland to islands.

\section{Sex-biased dispersal}

Comparisons using biparentally and uniparentally inherited markers supported the hypothesis of moderately female-biased gene flow. After adjusting for different $N_{e}$ (by dividing nuclear estimates by four under the assumption of equal sex ratios) modal values for total migration rates (immigration and emigration rates combined) were higher for mtDNA than for microsatellites (Table 3). Modal values for $\mathrm{Nm}$ from the islands to the mainland were on average two to four times higher for mtDNA, than modal values estimated from microsatellite markers although the $\mathrm{Nm}$ estimates from mtDNA showed large confidence limits. By contrast, $\mathrm{Nm}$ estimates were lower for mtDNA markers than microsatellite markers for gene flow from mainland to island clusters across all comparisons.

The Z-chromosomal microsatellite marker exhibited more genetic structure than the 21 autosomal markers (Median $F_{\mathrm{ST}} \mathrm{Z} \delta=0.042$; Median $F_{\mathrm{ST} \text { aut }}=0.036, P=0.003$ ). Genetic differentiation tended to be higher in adult males than females for two of the three tests that compared summary statistics of biparentally inherited markers between the sexes $\left(F_{\mathrm{ST} \delta}=\right.$ $\left.0.063, F_{\mathrm{ST} P}=0.049, P=0.068 ; R_{\widehat{\delta}}=0.12, R_{\varnothing}=0.09, P=0.058\right)$, although there was no such trend in $F_{\mathrm{IS}}\left(F_{\mathrm{IS} \delta}=0.022, F_{\mathrm{IS} q}=0.037, P=0.24\right)$.

\section{Discussion}

Our results demonstrate unusually high gene flow across large geographic distances in a terrestrial bird species using mtDNA, autosomal and Z-linked microsatellites. Bayesian 
analyses of mtDNA and autosomal microsatellite loci show that mainland Kentish plovers are largely genetically undifferentiated across continental Eurasia and Africa. The genetic pattern of continental sampling locations which were separated by up to $10,000 \mathrm{~km}$ resembled the pattern in a single panmictic population. This lack of genetic structure cannot be explained by homoplasy of microsatellite markers or, by low power of the applied marker set, since we detected genetic differentiation of ocean island populations and the panmixia pattern derived from mtDNA was consistent with the pattern observed at microsatellites. Island populations were moderately differentiated from the mainland populations and genetic differentiation increased with distance of the islands from mainland.

When analyzing patterns of genetic differentiation it is important to disentangle current gene flow from demographic processes that occurred in the population history (Avise 1994). Low genetic structure and sharing of haplotypes are seen in many species that have undergone a bottleneck and shifted their geographic distributions in response to climate oscillations such as the last glacial maximum (e.g. Hewitt 2000; Wenink et al. 1994). However, we argue that it is unlikely that the last glacial maximum has caused a profound shift of the Kentish plover distribution. First, in contrast to inhabitants of higher latitudes most of the present distribution of Kentish plovers was not covered by the ice sheet during the last glacial maximum. The center of the current distribution in Southern Europe, North Africa and Asia provided sufficient suitable habitats to maintain a substantial population (Cramp \& Simmons 1983; Harrison \& Prentice 2003). Second, we did not detect any evidence for population bottlenecks or expansions at mtDNA or microsatellite markers for the continental population. Furthermore, the observed lack of an isolation-by-distance pattern supports the view that lack of structure is caused by high contemporary gene flow.

Lack of genetic structure across large geographic distances is rare among terrestrial animals and has only been described in a handful of insects and birds (Beverdige \& Simmons 2006; Estoup et al. 1996; Funk et al. 2007; Reudink et al. 2011; Verkuil et al. 2012). By contrast, most other terrestrial species show at least modest genetic structure (Avise 2000). Based on the breeding ecology we offer two explanations for the high gene flow. First, Kentish plovers often breed in temporarily available habitats such as salt marshes, alkaline lakes and fish 
ponds and the long breeding season (which lasts up to 5 months) provides opportunities for several successful breeding attempts per year (Kosztolányi et al. 2009; Székely \& Lessells 1993). Local breeding locations at temporal salt lakes are often unstable and only suitable for a fraction of the available breeding time promoting mobility of the breeders. Unpredictable and unstable habitats have been proposed to explain panmixia in Dawson's burrowing bees Amegilla dawsoni (Beverdige \& Simmons 2006). Second, resighting and genetic data suggest high breeding dispersal particularly by females. During the reproductive season Kentish plover females can breed at sites hundreds of kilometers apart which will prevent breeding locations from differentiation (Székely \& Lessells 1993).

The results of the sex-biased gene flow analyses are concordant with resighting data, and suggest a prominent role for females to maintain high gene flow between breeding locations. We found higher estimates for migration rates and lower genetic structure (i.e. lower number of significant pairwise comparisons) for maternally inherited mtDNA than biparentally inherited autosomal microsatellites. This is unexpected on purely population genetic grounds because the $N_{e}$ of mtDNA is smaller than the corresponding $N_{e}$ of nuclear microsatellites, and mtDNA genetic markers should therefore coalesce faster (Ballard \& Whitlock 2004; Edwards et al. 2005). The Bayesian phylogeny based on mtDNA was very shallow and branch support was poor or not in agreement with geographic sample origin. Models that restricted the mtDNA haplotypes to their geographic origin received less support than the unconstrained model. Genetic differentiation of island populations followed a linear isolation-by-distance pattern for autosomal markers, but not for the maternally inherited mtDNA marker.

In principle, the apparently higher $\mathrm{Nm}$ estimates for mtDNA may have been an artifact of differences between nuclear and mtDNA. We think that this is unlikely to affect our conclusion for three reasons. First, mutation rates of microsatellites are assumed to be higher than for the mtDNA control region (Buehler \& Baker 2005; Ellegren 2000) but immigration rates $\left(x N_{m}\right)$ in MIGRATE do not rely on mutation rates since they are calculated by multiplying $\Theta$ (equivalent to $N_{e}$ multiplied with mutation rate per site per generation) with the mutation scaled immigration rate $M$ (equivalent to the immigration rate divided by the mutation rate per site per generation, Beerli 2010). 
Second, selection regimes may differ between microsatellites and mtDNA. The characteristics of the genetic markers that we used probably did not differ from those of neutral markers. Microsatellites are generally assumed to be largely neutral markers and all of the microsatellite markers we used were located in presumably non-coding regions (Küpper et al. 2008). For the mtDNA Tajima's D values were nonsignificant suggesting that selection is not operating on the D-loop in the Kentish plover.

Thirdly, differences in $N_{e}$ between the maternally and biparentally inherited markers should also not change our conclusion about female-biased gene flow. The assumption that $N_{e}$ for nuclear markers is about four times larger than for mtDNA holds only if the adult sex ratio is 1:1 (Wright et al. 2005). It is possible that this assumption of an equal adult sex ratio is violated in polyandrous Kentish plovers. A recent study showed that in at least one population sex-biased chick mortality leads to a strong adult male bias with more than six males per female (Kosztolányi et al. 2011). No Kentish plover population with an adult female bias is known and most bird populations appear to have a male skewed adult sex ratio (Donald 2007). An adult male bias over the entire range of the species would further increase our estimates for female-biased gene flow for mtDNA and autosomal marker comparisons and therefore we regard our current estimates for the sex-bias as conservative.

The results of the comparison of genetic differentiation at the Z-chromosomal marker and the autosomal markers provided further support for female-biased gene flow. Estimates for genetic differentiation were higher for the Z-chromosomal marker than for the autosomal markers. In an analogous investigation of sex-biased dispersal in humans Ségurel et al. (2008) modeled the observed outcomes for genetic differentiation (measured as $F_{S T}$ ) for comparisons between X-chromosomal and autosomal markers for differing population sex ratios and sex-biased migration rates using Wright's infinite island model of population structure. Using the observed sixfold excess of adult males in a Kentish plover breeding population (Kosztolányi et al. 2011), and adjusting for the ZW system, the model suggests female-biased gene flow as the most likely explanation for higher genetic differentiation of Z-chromosomal markers than autosomal markers. 
The previous results are based on comparisons involving estimates derived from a single marker for $\mathrm{Z}$ chromosome and mtDNA. Such comparisons alone can be misleading because single marker statistics will be strongly influenced by stochastic effects (Edwards et al. 2005). However, we also found support for female-biased gene flow from multilocus analyses of sex-biased dispersal. Population differentiation and relatedness were marginally higher for adult males than females of different geographically coherent clusters. Despite the consistency of the sex-bias dispersal analysis across the three different marker comparisons the bias appeared to be of only moderate magnitude. Moderate sex-biased dispersal can be hard to detect particularly when sample sizes are small. Moreover, any bias will fade away in subsequent generations when migrants have been integrated into the breeding population (Goudet et al. 2002; Prugnolle \& de Meeus 2002).

It is also possible that the sex-biased gene flow is reduced by male natal dispersal. Higher natal dispersal by males has been reported in other polyandrous shorebirds (Clarke et al. 1997). We can only indirectly test natal dispersal using recruitment data since ringing recoveries of Kentish plover juveniles are scarce. Recruitment in two Kentish plover populations which were studied over a period of five or more years showed no sex bias: at FDP a total of 16 males and 17 females that were ringed at hatching were recruited subsequently (Amat et al. 2001), and similarly, at TUZ 32 male and 29 female recruits were caught over five field seasons (T Székely, A Kosztolányi, C Küpper, unpublished results). Based on the observed strong adult male bias in polyandrous populations the number of male recruits is surprisingly low and concordant with male-biased natal dispersal.

Phylogeographic studies of Charadrius species seem to support a role of mating systems on population genetic structure. The closely related snowy plover shares many breeding biology characteristics with the Kentish plover such as multiple clutches, polygamy and nesting in unstable habitats (e.g. Page et al. 1995; Warriner et al. 1986). A number of snowy plover populations are well monitored and a wealth of resighting data has been accumulated over the last decades. Both snowy plover males and females are highly site faithful and more than $95 \%$ of male and female chicks return to breed at their natal sites in subsequent years 
several locations up to $660 \mathrm{~km}$ (females) and $840 \mathrm{~km}$ (males) apart (Stenzel et al. 1994). Consistently, snowy plovers do not exhibit genetic structure across their North American continental range (Funk et al. 2007). Lack of genetic structure was also found in another plover species with a multiple clutch system the mountain plover C. montanus (OylerMcCance et al. 2008). In contrast, moderate population structure has been observed on a relatively small spatial scale in the monogamous piping plover C. melodus (Miller et al. 2010). Additional genetic studies of monogamous and low latitude breeders in this genus are needed to examine the association between mating systems and population genetics.

The analysis and comparison of genetic diversity and gene flow provided further insights into the phylogeography of Kentish plovers. Gene flow was asymmetric with higher rates from the islands towards the mainland for the Macaronesian populations located in the Atlantic Ocean. This pattern may be driven by size differences among different landmasses. The Macaronesian island archipelagos are remote and relatively small. Therefore, the plovers emigrating from the mainland westwards are unlikely to encounter them. By contrast, Eurasia and Africa form a large continental land mass and therefore emigrating plovers from Macaronesia that fly east will almost certainly reach the continent breeding sites if they are able to cover the distance. The situation is different for the Asian islands where the bias in the direction of gene flow is smaller. Farasan Islands are located close to the mainland $(<40 \mathrm{~km})$ whereas the East Asian islands of Japan, Taiwan and Okinawa are also relatively close to the mainland coast and of larger size than the Macaronesian islands. Therefore more mainland plovers are more likely to reach these East Asian islands than the Macaronesian islands.

Despite the overall female biased gene flow we observed an interesting switch of sex-biased gene flow. Low mean values of mtDNA and higher mean values for microsatellites suggested male biased gene flow from the mainland to the islands whereas strongly female biased gene flow was observed from the islands to the mainland (Table 3). This apparent difference in sex-biased gene flow could have two explanations. Firstly, mainland and island plovers may differ in their dispersal behavior or capabilities with island females and mainland males dispersing further and the opposite sex dispersing less. Sex differences in migratory behavior are known from other shorebird species with males and females wintering at different 
locations (Gill et al. 1995; Nebel et al. 2002) although it is not known whether these sex differences are population specific. However, we think that in Kentish plovers this is unlikely because mainland females but not males were observed at distant breeding sites (Székely \& Lessells 1993). Secondly, the apparent male bias could be an artifact since for the mainland to island comparisons the confidence intervals for mtDNA were large and exceeded those of the microsatellites. Further studies are needed to test the whether the apparent asymmetrical sex-biased gene flow has a biological meaning.

Island populations exhibited lower genetic diversity than mainland sites. This pattern has been found in many other taxa using different marker types (Frankham 1997). However, the genetic differentiation of the island populations was surprising because plovers are excellent dispersers, live in both marine and terrestrial habitats, and we observed no genetic structure on the continent. Islands close to the mainland $(<100 \mathrm{~km})$ were only poorly differentiated whereas more remote islands were well differentiated. Therefore we conclude that large ocean stretches provide effective physical barriers for gene flow in Kentish plovers. The negligible genetic differentiation of island populations close to the continent may explain the discrepancies of the results between the two Bayesian clustering approaches. However, Bayesian clustering analyses clearly showed that the wintering population of Kentish plovers sampled in Taiwan consisted of a mix of migrating plovers from the mainland and Taiwan residents.

The old age of the island archipelagos - the youngest island group is more than 20 million years old - prevented us from using geological data for calibration to time the island colonization events by Kentish plovers. We found signs of recent population declines at the Azores and Canary island populations (STM and FUV) and there was a similar although nonsignificant trend for the Cape Verde population (CVM). Low sample sizes did not allow us to test for population fluctuations at Porto Santo (PST), the fourth remote Macaronesian location, where we only found a single breeding pair and two of the three Asian clusters (JPN and $\mathrm{OKN}$ ). As in other analyses, the nuclear markers were more informative in recovering the demographic history than the mtDNA marker. 
639 In conclusion, we found no genetic structure in Kentish plovers on a continental scale. By 640 contrast, island populations were moderately differentiated from the mainland population and 641 genetic differentiation increased with ocean distance that separated breeding locations. A 642 comparison of differentiation and migration rates between mtDNA, a Z-linked microsatellite 643 marker and 21 microsatellite markers suggests that high gene flow is mediated through 644 dispersal of breeding females. Future work should focus on the effects of the mating system 645 and reproductive biology on genetic differentiation in this taxonomic group.

\section{Acknowledgments}

648 We are grateful to Wei-Ting Liu, Lei Ming and Yoshi Shigeta for providing blood samples 649 and Jakob Augustin for help with genetic analyses. We thank Maude Baldwin, and three 650 anonymous reviewers for comments that helped to improve this manuscript. Funding for 651 fieldwork was provided by the National Geographic Society (8403-08). Laboratory work was 652 funded by the Natural Environmental Research Council (MGF184) and conducted at NBAF, 653 University of Sheffield. CK was supported by a postdoctoral fellowship of German Academic 654 Exchange Service. AK was supported by the Hungarian Scientific Research Fund (OTKA, 655 K81953 to Ádám Miklósi). JAA was supported by Junta de Andalucía (RNM361), AAT was 656 supported by the Mexican National Council of Science and Technology. 
657

658

659

660

661

662

663

664

665

666

667

668

669

670

671

672

673

674

675

676

677

678

679

680

681

682

683

684

685

686

687

688

689

690

691

\section{References}

Akaike H (1974) A new look at the statistical model identification. Ieee Transactions on Automatic Control AC19, 716-723.

Amat JA, Fraga RM, Arroyo GM (1999) Brood desertion and polygamous breeding in the Kentish Plover Charadrius alexandrinus. Ibis 141, 596-607.

Amat JA, Fraga RM, Arroyo GM (2001) lntraclutch egg-size variation and offspring survival in the Kentish Plover Charadrius alexandrinus. Ibis 143, 17-23.

Avise JC (1994) Molecular markers, natural history, and evolution Chapman \& Hall, New York.

Avise JC (2000) Phylogeography: The History and Formation of Species Harvard University Press, Cambridge.

Avise JC (2004) Molecular markers, natural history and evolution Sinauer Associates, Sunderland, MA.

Ballard JWO, Whitlock MC (2004) The incomplete natural history of mitochondria. Molecular Ecology 13, 729-744.

Balloux F, Lugon-Moulin N (2002) The estimation of population differentiation with microsatellite markers. Molecular Ecology 11, 155-165.

Beerli P (2010) MIGRATE Documentation version 3.2. Florida State University, Tallahassee.

Belkhir K, Borsa P, Chikhi L, Raufaste N, Bonhomme F (1996-2004) GENETIX 4.05, logiciel sous Windows TM pour la génétique des populations. Laboratoire Génome, Populations, Interactions, CNRS UMR 5171, Université de Montpellier II, Montpellier.

Beverdige M, Simmons LW (2006) Panmixia: an example from Dawson's burrowing bee (Amegilla dawsoni) (Hymenoptera: Anthophorini). Molecular Ecology 15, 951-957.

Bohonak AJ (1999) Dispersal, gene flow and population structure. The Quarterly Review of Biology 75, 21-45.

Bouzat JP, Johnson K (2004) Genetic structure among closely spaced leks in a peripheral population of lesser prairie-chickens. Molecular Ecology 13, 499-505.

Buehler DM, Baker AJ (2005) Population divergence times and historical demography in red knots and dunlins. Condor 107, 497-513.

Capparoz R, Miyaki CY, Baker AJ (2009) Contrasting phylogeographic patterns in mitochondrial DNA and microsatellites: evidence of female philopatry and malebiased gene flow among regional populations of the blue-and-yellow macaw (Psittaciformes: Ara ararauna) in Brazil. Auk 126, 359-370. 
Carling MD, Lovette IJ, Brumfield RT (2010) Historical divergence and gene flow: coalescent analyses of mitochondrial, autosomal and sex-linked loci in Passerina buntings. Evolution 64, 1762-1772.

Chen C, Durand E, Forbes F, François O (2007) Bayesian clustering algorithms ascertaining spatial population structure: A new computer program and a comparison Study. Molecular Ecology Notes 7, 747-756.

Clarke AL, Saether BE, Røskaft E (1997) Sex biases in avian dispersal:a reappraisal. OIKOS 79, 429-438.

Clobert J, Ims RA, Rousset F (2004) Causes, mechanisms and consequences of dispersal. In: Ecology, genetics and evolution of metapopulations (eds. Hanski I, Gaggiotti OE), pp. 307-335. Elsevier, Burlington, MA.

Cornuet JM, Luikart G (1996) Description and power analysis of two tests for detecting recent population bottlenecks from allele frequency data. Genetics 144, 2001-2014.

Cramp S, Simmons KEL (1983) Handbook of the birds of Europe, the Middle East and North Africa Oxford University Press, New York.

del Hoyo J, Elliot A, Sargatal J (1996) Handbook of the birds of the world. Hoatzin to Auks Lynx edicions, Barcelona.

Donald PF (2007) Adult sex ratios in wild bird populations. Ibis 149, 671-692.

Dowling DK, Friberg U, Lindell J (2008) Evolutionary implications of non-neutral mitochondrial genetic variation. Trends in Ecology \& Evolution 23, 546-554.

Edwards SV (1994) Long distance gene flow in a cooperative breeder detected in the genealogies of mitochondrial DNA. Proceedings of the Royal Society B: Biological Sciences 252, 177-185.

Edwards SV, Kingan SB, Calkins JD, et al. (2005) Speciation in birds: Genes, geography, and sexual selection. Proceedings of the National Academy of Sciences of the USA 102, 6550-6557.

Ellegren H (2000) Microsatellite mutations in the germline: implications for evolutionary inference. Trends in Genetics 16, 551-558.

Estoup A, Solignac M, Cornuet JM, Goudet J, Scholls A (1996) Genetic differentiation of continental and island populations of Bombus terrestris (Hymenoptera: Apidae) in Europe. Molecular Ecology 5, 19-31.

Evanno G, Regnaut C, Goudet J (2005) Detecting the number of clusters of individuals using the software STRUCTURE: a simulation study. Molecular Ecology 14, 2611-2620.

Excoffier L, Laval G, Schneider S (2005) Arlequin ver. 3.0: An integrated software package for population genetics data analysis. Evolutionary Bioinformatics Online 1, 47-50.

Frankham R (1997) Do island populations have less genetic variation than mainland populations? Heredity 78, 311-327. 
Funk WC, Mullins TD, Haig SM (2007) Conservation genetics of snowy plovers (Charadrius alexandrinus) in the Western Hemisphere: population genetic structure and delineation of subspecies. Conservation Genetics 8, 1287-1309.

Gibbs HL, Dawson RJG, Hobson KA (2000) Limited differentiation in microsatellite DNA variation among northern populations of the yellow warbler: evidence for male-biased gene flow? Molecular Ecology 9, 2137-2147.

Gill JA, Clark J, Clark N, Sutherland WJ (1995) Sex differences in the migration, moult and wintering areas of British-ringed Ruff. Ringing \& Migration 16, 159-167.

Goudet J, Perrin N, Waser P (2002) Tests for sex-biased dispersal using bi-parentally inherited genetic markers. Molecular Ecology 11, 1103-1114.

Greenwood PJ (1980) Mating systems, philopatry and dispersal in birds and mammals. Animal Behaviour 28, 1140-1162.

Harrison SP, Prentice AI (2003) Climate and $\mathrm{CO}_{2}$ controls on global vegetation distribution at the last glacial maximum: analysis based on palaeovegetation data, biome modelling and palaeoclimate simulations. Global Change Biology 9, 983-1004.

Hefti-Gautschi B, Pfunder M, Jenni L, Keller V, Ellegren H (2009) Identification of conservation units in the European Mergus merganser based on nuclear and mitochondrial DNA markers. Conservation Genetics 10, 87-99.

Hewitt G (2000) The genetic legacy of the Quaternary ice ages. Nature 405, 907-913.

Jakobsson M, Rosenberg NA (2007) CLUMPP: a cluster matching and permutation program for dealing with label switching and multimodality in analysis of population structure. Bioinformatics 23, 1801-1806.

Johnson T, Toepfer JE, Dunn PO (2003) Contrasting patterns of mitochondrial and microsatellite population structure in fragmented populations of greater prairiechickens. Molecular Ecology 12, 3335-3347.

Kass RE, Raftery AE (1995) Bayes factors. Journal of the American Statistical Association 90, 773-795.

Kosztolányi A, Barta Z, Küpper C, Székely T (2011) Persistence of an extreme male-biased adult sex ratio in a natural population of polyandrous bird. Journal of Evolutionary Biology.

Kosztolányi A, Javed S, Küpper C, et al. (2009) Breeding ecology of Kentish Plover Charadrius alexandrinus in an extremely hot environment. Bird Study 56, 244-252.

Küpper C, Augustin J, Kosztolányi A, et al. (2009) Kentish versus Snowy Plover: Phenotypic and genetic analyses of Charadrius alexandrinus reveal divergence of Eurasian and American subspecies. Auk 126, 839-852.

Küpper C, Burke T, Székely T, Dawson DA (2008) Enhanced cross-species utility of conserved microsatellite markers in shorebirds. BMC Genomics 9, 502. 
Küpper C, Horsburgh GJ, Dawson DA, et al. (2007) Characterization of 36 polymorphic microsatellite loci in the Kentish plover (Charadrius alexandrinus) including two sexlinked loci and their amplification in four other Charadrius species. Molecular Ecology Notes 7, 35-39.

Lawson Handley LJ, Perrin N (2007) Advances in our understanding of mammalian sexbiased dispersal. Molecular Ecology 16, 1559-1578.

Lessells CM (1984) The mating system of Kentish plovers Charadrius alexandrinus. Ibis 126, 474-483.

Li MH, Merilä J (2010) Genetic evidence for male-biased dispersal in the Siberian jay (Perisoreus infaustus) based on autosomal and Z-chromosomal markers. Molecular Ecology 19, 5281-5295.

Librado P, Rozas J (2009) DnaSP v5: A software for comprehensive analysis of DNA polymorphism data. Bioinformatics 25, 1451-1452.

Liu Y, Keller I, Heckel G (2012) Breeding site fidelity and winter admixture in a longdistance migrant, the tufted duck (Aythya fuligula). Heredity 109, 108-116.

Mäki-Petäys H, Corander J, Aalto J, et al. (2007) No genetic evidence of sex-biased dispersal in a lekking bird, the capercaillie (Tetrao urogallus). Journal of Evolutionary Biology 20, 865-873.

Miller MP, Haig SM, Gratto-Trevor CL, Mullins TD (2010) Subspecies status and population genetic structure in piping plover (Charadrius melodus). Auk 127, 57-71.

Nebel S, Lank DB, O'Hara PD, et al. (2002) Western sandpipers (Calidris mauri) during the nonbreeding season: Spatial segregation on a hemispheric scale. Auk 119, 922-928.

Nylander JAA (2004) MrModeltest v2. Program distributed by the author (ed. Evolutionary Biology Centre UU).

Nylander JAA, Ronquist F, Huelsenbeck JP, Nieves-Aldrey JL (2004) Bayesian Phylogenetic Analysis of Combined Data. Systematic Biology 53, 47-67.

Okamura B, Freeland JR (2002) Gene flow and the evolutionary ecology of passively dispersing aquatic invertebrates. In: Dispersal Ecology (eds. Bullock JM, Kenward RE, Hails RS), pp. 194-216. Blackwell Science, Malden, MA.

Oyler-McCance SJ, St John J, Kysela RF, Knopf FL (2008) Population structure of mountain plover as determined using nuclear microsatellites. Condor 110, 493-499.

Page GW, Warriner JS, Warriner JC, Paton PWC (1995) Snowy plover Charadrius alexandrinus. In: The Birds of North America (eds. Poole A, Gill F). The Academy of Natural Sciences, Philadelphia, and The American Ornithologists' Union, Washington, DC.

Piertney SB, MacColl ADC, Bacon PJ, et al. (2000) Matrilineal genetic structure and femalemediated gene flow in red grouse (Lagopus lagopus scoticus): an analysis using mitochondrial DNA. Evolution 54, 279-289. 
Pritchard JK, Stephens M, Donnelly P (2000) Inference of population structure using multilocus genotype data. Genetics 155, 945-959.

Prugnolle F, de Meeus T (2002) Inferring sex-biased dispersal from population genetic tools: a review. Heredity 88, 161-165.

R Development Core Team (2010) R: A language and environment for statistical computing. R Foundation for Statistical Computing, Vienna, Austria. Available at http://www.Rproject.org

Reudink MW, Kyle CJ, Nocera JJ, et al. (2011) Panmixia on a continental scale in a widely distributed colonial waterbird. Biological Journal of the Linnean Society 102, 583592.

Rheindt FE, Székely T, Edwards SV, et al. (2011) Conflict between genetic and phenotypic differentiation: the evolutionary history of a 'lost and rediscovered' shorebird. PLoS one 6, e26995.

Rönkä A, Kvist L, Karvonen J, et al. (2008) Population genetic structure in the Temminck's stint Calidris temminckii, with an emphasis on Fennoscandian populations. Conservation Genetics 9, 29-37.

Rönkä N, Kvist A, Pakanen VM, et al. (2012) Phylogeography of the Temminck's Stint (Calidris temminckii): historical vicariance but little present genetic structure in a regionally endangered Palearctic wader. Diversity and Distributions.

Ronquist F, Huelsenbeck JP (2003) MrBayes 3: Bayesian phylogenetic inference under mixed models. Bioinformatics 19, 1572-1574.

Rosenberg NA (2004) Distruct: a program for the graphical display of population structure. Molecular Ecology Notes 4, 137-138.

Rousset F (1997) Genetic differentiation and estimation of gene flow from F-statistics under isolation by distance. Genetics 145, 1219-1228.

Scribner KT, Petersen MR, Fields RL, et al. (2001) Sex-biased gene flow in spectacled eiders (anatidae): inferences from molecular markers with contrasting modes of inheritance. $\mathbf{5 5}, 2105-2115$.

Ségurel L, Martínez-Cruz B, Quintana-Murci L, et al. (2008) Sex-specific genetic structure and social organization in central asia: insights from a multi-locus study. PLOS Genetics 4.

Seutin G, White BN, Boag PT (1991) Preservation of avian blood and tissue samples for DNA analyses. Canadian Journal of Zoology 69, 82-90.

Slatkin M (1995) A measure of population subdivision based on microsatellite allele frequencies. Genetics 139, 457-462.

Stenzel LE, Page GW, Warriner JC, et al. (2011) Male-skewed adult sex ratio, survival, mating opportunity and annual productivity in the Snowy Plover Charadrius alexandrinus. Ibis 153, 312-322. 
Stenzel LE, Warriner JC, Warriner JS, et al. (1994) Long-distance breeding dispersal of snowy plovers in Western North America. Journal of Animal Ecology 63, 887-902.

Storey J (2002) A direct approach to false discovery rates. Journal of the Royal Statistical Society: Series B 64, 479-498.

Székely T, Cuthill IC, Kis J (1999) Brood desertion in Kentish plover: sex differences in remating opportunities. Behavioral Ecology 10, 185-190.

Székely T, Kosztolanyi A, Küpper C (2008) Practical guide for investigating breeding ecology of Kentish plover Charadrius alexandrinus. University of Bath.

Székely T, Lessells CM (1993) Mate change by Kentish Plovers Charadrius alexandrinus. Ornis Scandinavica 24, 317-322.

Verkuil YI, Piersma T, Jukema J, et al. (2012) The interplay between habitat availability and population differentiation: a case study on genetic and morphological structure in an inland wader (Charadriiformes). Biological Journal of the Linnean Society.

Warriner JS, Warriner JC, Page GW, Stenzel LE (1986) Mating system and reproductive success of a small population of polygamous snowy plovers. Wilson Bulletin 98, 1537.

Wenink PW, Baker AJ, Tilanus MGJ (1994) Mitochondrial control region sequences in two shorebird species, the turnstone and the dunlin, and their utility in population genetic studies. Molecular Biology and Evolution 11, 22-31.

Wright TF, Rodriguez AM, Fleischer RC (2005) Vocal dialects, sex-biased dispersal, and microsatellite population structure in the parrot Amazona auropalliata. Molecular Ecology 14, 1197-1205. 
Table 1. Details of geographic locations and sample sizes for mitochondrial and microsatellite markers of 21 Kentish plover sites sampled.

\begin{tabular}{|c|c|c|c|c|c|c|c|c|c|}
\hline Site & Country & Abbreviation & Latitude & Longitude & Category & Status & Year & $N_{\text {mito }}$ & $N_{\text {micro }}$ \\
\hline Santa Maria & Azores/Portugal & STM & $36^{\circ} 58^{\prime} \mathrm{N}$ & $25^{\circ} 06^{\prime} \mathrm{W}$ & I & B & 2009 & 16 & 25 \\
\hline Fuerteventura & Canary Islands/Spain & FUV & $28^{\circ} 26^{\prime} \mathrm{N}$ & $14^{\circ} 00^{\prime} \mathrm{W}$ & I & B & 2009 & 17 & 25 \\
\hline Porto Santo & Madeira Islands/Portugal & PST & $33^{\circ} 04^{\prime} \mathrm{N}$ & $16^{\circ} 21^{\prime} \mathrm{W}$ & I & B & 2009 & 2 & 2 \\
\hline Samouco & Portugal & SAM & $38^{\circ} 43^{\prime} \mathrm{N}$ & $09^{\circ} 00^{\prime} \mathrm{W}$ & $\mathrm{M}$ & B & 2009 & 17 & 25 \\
\hline Gharifa & Morocco & GHR & $\begin{array}{l}35^{\circ} 09^{\prime}- \\
35^{\circ} 34^{\prime} \mathrm{N}\end{array}$ & $\begin{array}{l}05^{\circ} 59^{\prime}- \\
06^{\circ} 07^{\prime} \mathrm{W}\end{array}$ & $\mathrm{M}$ & B & 2009 & 12 & 11 \\
\hline Doñana & Spain & DON & $36^{\circ} 56^{\prime} \mathrm{N}$ & $06^{\circ} 21^{\prime} \mathrm{W}$ & $\mathrm{M}$ & B & 2004 & 17 & 25 \\
\hline Fuente de Piedra & Spain & FDP & $37^{\circ} 06^{\prime} \mathrm{N}$ & $04^{\circ} 45^{\prime} \mathrm{W}$ & $\mathrm{M}$ & B & 2006 & 17 & 25 \\
\hline Beltringharder Koog & Germany & BLK & $54^{\circ} 32^{\prime} \mathrm{N}$ & $08^{\circ} 54^{\prime} \mathrm{E}$ & M & B & 2009 & 10 & 13 \\
\hline Kujalnik & Ukraine & KUJ & $46^{\circ} 45^{\prime} \mathrm{N}$ & $30^{\circ} 36^{\prime} \mathrm{E}$ & M & B & 2006 & 17 & 15 \\
\hline Tuzla & Turkey & TUZ & $36^{\circ} 42^{\prime} \mathrm{N}$ & $35^{\circ} 03^{\prime} \mathrm{E}$ & $\mathrm{M}$ & B & 2004 & 16 & 25 \\
\hline Farasan Islands & Saudi Arabia & FAR & $16^{\circ} 48^{\prime} \mathrm{N}$ & $41^{\circ} 53^{\prime} \mathrm{E}$ & I & B & $2007-08$ & 16 & 25 \\
\hline Lake Elton & Russia & ELT & $49^{\circ} 12^{\prime} \mathrm{N}$ & $46^{\circ} 39^{\prime} \mathrm{E}$ & $\mathrm{M}$ & B & $2006-07$ & 16 & 14 \\
\hline Taiwan & Taiwan & TWB & $24^{\circ} 30^{\prime} \mathrm{N}$ & $120^{\circ} 40^{\prime} \mathrm{E}$ & $\mathrm{I}$ & $\mathrm{B}$ & $2005-06$ & 10 & 25 \\
\hline Taiwan & Taiwan & TWW & $24^{\circ} 30^{\prime} \mathrm{N}$ & $120^{\circ} 40^{\prime} \mathrm{E}$ & I & $\mathrm{W}$ & 2004-07 & 8 & 22 \\
\hline Okinawa & Japan & OKN & $26^{\circ} 11^{\prime} \mathrm{N}$ & $127^{\circ} 43^{\prime} \mathrm{E}$ & I & $\mathrm{B}$ & 2006-07 & 3 & 3 \\
\hline Japan & Japan & JAP & $35^{\circ} 52^{\prime} \mathrm{N}$ & $140^{\circ} 45^{\prime} \mathrm{E}$ & $\mathrm{I}$ & $\mathrm{B}$ & 2004-09 & 6 & 7 \\
\hline
\end{tabular}

$866 N_{\text {mito }}$, number of individuals for which a part of the control region was sequenced; $N_{\text {micro }}$, number of individuals genotyped at microsatellite loci;

$867 I$, island; $M$, mainland; $B$, breeding population; $W$, wintering population 
Table 2. Genetic diversity of 20 breeding locations for Kentish plover measured by $427 \mathrm{bp}$ fragment of the mitochondrial control region and 21 autosomal microsatellite markers

\begin{tabular}{llllllllll}
\hline Population & \multicolumn{1}{l}{ mtDNA } & \multicolumn{7}{c}{ Microsatellites } \\
& $n_{H T}$ & $h$ & $\pi$ & $D_{T}$ & $A$ & $A_{\text {rich }}$ & $H_{O}$ & $H_{e}$ & $P_{T P M}$ \\
\hline Island & & & & & & & & & \\
STM & 2 & 0.13 & 0.0002 & -1.16 & 4.9 & 2.53 & 0.66 & 0.66 & 0.002 \\
CVB & 2 & 0.67 & 0.0016 & na & 5 & 2.53 & 0.63 & 0.69 & 0.065 \\
CVM & 3 & 0.62 & 0.0054 & 1.44 & 6 & 2.53 & 0.63 & 0.68 & 0.20 \\
FUV & 4 & 0.71 & 0.0033 & 0.59 & 8.2 & 2.85 & 0.76 & 0.77 & 0.007 \\
PST & 1 & 0 & 0 & na & 1.8 & 2 & 0.57 & 0.50 & na \\
FAR & 5 & 0.71 & 0.0039 & 0.42 & 8 & 2.77 & 0.71 & 0.76 & 0.39 \\
TWB & 7 & 0.95 & 0.0078 & -0.80 & 8.3 & 2.8 & 0.72 & 0.76 & 0.34 \\
OKN & 2 & 0.67 & 0.0031 & na & 3.2 & 2.66 & 0.80 & 0.70 & na \\
JAP & 3 & 0.60 & 0.0045 & na & 5.3 & 2.81 & 0.76 & 0.77 & na \\
& & & & & & & & & \\
Mainland & & & & & & & & & \\
SAM & 8 & 0.77 & 0.0039 & -0.7 & 9.6 & 2.94 & 0.76 & 0.78 & 0.45 \\
GHR & 5 & 0.67 & 0.0039 & -0.59 & 6.4 & 2.82 & 0.74 & 0.74 & 0.52 \\
DON & 8 & 0.85 & 0.004 & -0.58 & 9.7 & 3.03 & 0.76 & 0.79 & 0.29 \\
FDP & 5 & 0.81 & 0.0042 & 0.68 & 9.4 & 2.95 & 0.78 & 0.79 & 0.73 \\
BLK & 5 & 0.76 & 0.004 & -0.18 & 7.2 & 2.83 & 0.74 & 0.77 & 1 \\
KUJ & 11 & 0.91 & 0.0059 & -0.85 & 8.0 & 2.95 & 0.75 & 0.80 & 0.07 \\
TUZ & 8 & 0.83 & 0.0042 & -0.51 & 10.3 & 3.11 & 0.79 & 0.81 & 0.87 \\
ELT & 11 & 0.95 & 0.0071 & -0.34 & 7.9 & 2.99 & 0.81 & 0.80 & 0.22 \\
ALW & 8 & 0.86 & 0.0049 & -0.46 & 9.8 & 2.95 & 0.81 & 0.79 & 0.68 \\
XIN & 6 & 0.83 & 0.0059 & -0.68 & 5.6 & 2.8 & 0.69 & 0.79 & na \\
BOH & 2 & 0.60 & 0.0014 & na & 5.2 & 3 & 0.73 & 0.80 & na \\
All Mainland & 41 & 0.83 & 0.0047 & -1.66 & 15.6 & 2.89 & 0.77 & 0.80 & 0.36 \\
\hline
\end{tabular}

$n_{H T}$, number of haplotypes; $h$, haplotype diversity; $\pi$, nucleotide diversity; $D_{T}$, Tajima's $\mathrm{D} ; A$, number of alleles; $A_{\text {rich }}$, allelic richness; $H_{o}$, observed heterozygosity; $H_{e}$, expected heterozygosity; $P_{T P M}$, p-value for tests of heterozygosity deficiency and excess using the two-phased mutation model in BOTTLENECK 
Table 3. Estimates of $\Theta$ and $N m$ for genetic clusters of Kentish plovers estimated from 21 autosomal microsatellite markers and a 427 bp 874 fragment of the mitochondrial D-loop using MIGRATE. Due to differences in the mode of inheritance, $\Theta$ and $N m$ values estimated from 875 microsatellites were divided by four to make them comparable with corresponding values from mitochondrial DNA under the assumption of 876 equal sex ratios. Migration rates were averaged over two converged independent runs with five replicates. Modal values with $95 \%$ confidence 877 limits in parentheses are given.

\begin{tabular}{|c|c|c|c|c|c|c|c|}
\hline Population & $\Theta$ & Cape Verde $\rightarrow$ & Santa Maria $\rightarrow$ & Fuerteventura $\rightarrow$ & Mainland $\rightarrow$ & Farasan Islands $\rightarrow$ & East Asian Islands $\rightarrow$ \\
\hline \multicolumn{8}{|l|}{$M t D N A$} \\
\hline Cape Verde & $0.003(0-0.1)$ & & $0.3(0-14)$ & $0.3(0-14)$ & $0.3(0-14)$ & $0.3(0-14)$ & $0.3(0-14)$ \\
\hline Santa Maria & $0.003(0-0.1)$ & $0.3(0-14.3)$ & & $0.3(0-14)$ & $0.3(0-14.3)$ & $0.3(0-14.3)$ & $0.3(0-14.3)$ \\
\hline Fuerteventura & $0.003(0-0.1)$ & $0.3(0-14.7)$ & $0.3(0-14.7)$ & & $0.3(0-14.7)$ & $0.3(0-14.7)$ & $0.3(0-14.7)$ \\
\hline Mainland & $0.1(0-0.4)$ & $37.7(0-183)$ & $21.3(0-146.7)$ & $22.7(0-166)$ & & $13.3(0-129.3)$ & $23.7(0-138.7)$ \\
\hline Farasan Islands & $0.003(0-0.1)$ & $0.3(0-16.3)$ & $0.3(0-17.3)$ & $0.3(0-16.7)$ & $0.3(0-16.7)$ & & $0.3(0-16.3)$ \\
\hline East Asian Islands & $0.003(0-0.1)$ & $0.3(0-18)$ & $0.3(0-19)$ & $0.3(0-18.7)$ & $0.3(0-20.3)$ & $1(0-19)$ & \\
\hline \multicolumn{8}{|l|}{ Microsatellites } \\
\hline Cape Verde & $0.008(0-0.5)$ & & $0.1(0-3.8)$ & $0.1(0-3.8)$ & $4.1(0-8)$ & $0.1(0-3.8)$ & $0.1(0-3.9)$ \\
\hline Santa Maria & $0.008(0-0.4)$ & $0.1(0-3.7)$ & & $0.1(0-3.7)$ & $10(0-6.5)$ & $0.1(0-3.7)$ & $0.1(0-3.7)$ \\
\hline Fuerteventura & $0.3(0-0.7)$ & $0.1(0-4.8)$ & $0.1(0-4.5)$ & & $5.1(0.6-9.3)$ & $0.1(0-4.25)$ & $0.1(0-4.8)$ \\
\hline Mainland & $2.3(1.7-3)$ & $10(5.3-14.5)$ & $6.8(2.3-11.3)$ & $6.8(2.2-11.2)$ & & $6.8(2.1-11.2)$ & $8.9(4.3-13.4)$ \\
\hline Farasan Islands & $0.3(0-0.7)$ & $0.4(0-5.4)$ & $0.1(0-5)$ & $0.1(0-4.3)$ & $5.9(1.3-10.3)$ & & $0.1(0-7.1)$ \\
\hline East Asian Islands & $0.3(0-0.7)$ & $2.3(0-6.5)$ & $0.1(0-5.2)$ & $0.1(0-5.3)$ & $6.4(3.2-12.6)$ & $0.1(0-4.9)$ & \\
\hline
\end{tabular}




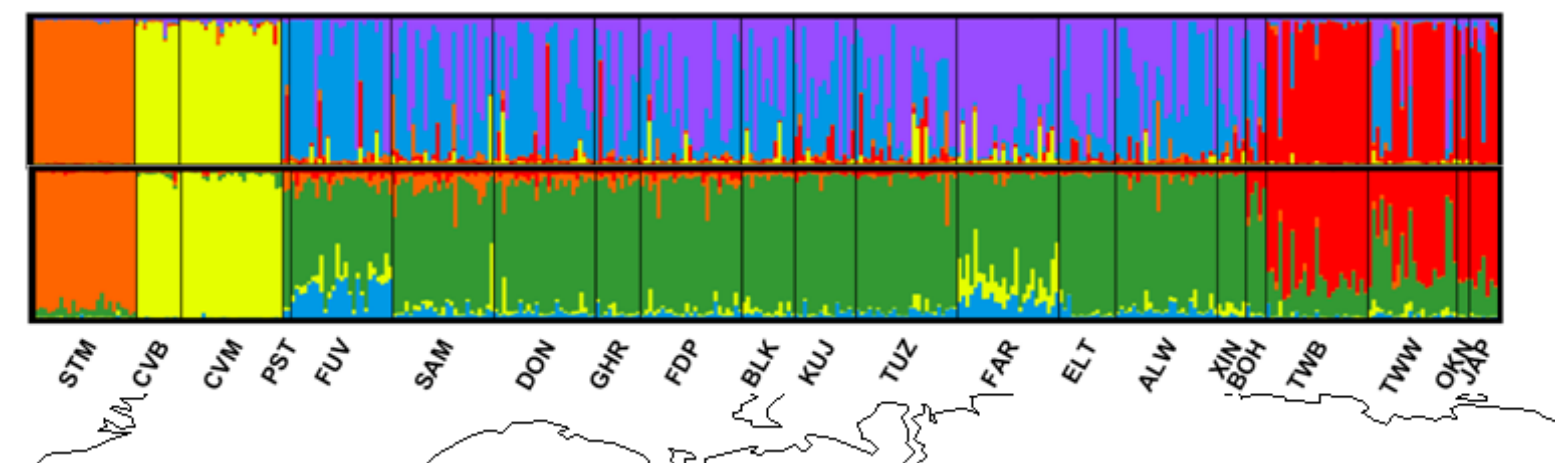

Figure 1. Map of sampling locations of 21 Kentish plover populations, and assignment into population clusters using STRUCTURE (top diagram) and TESS (lower diagram). Both programs suggested five clusters as the most likely value for $\mathrm{K}$ There was disagreement of assignment of Kentish plovers of three island populations PST, FUV and FAR (blue, turquoise and purple circles on map). According to STRUCTURE, plovers from mainland sites had genotypes 

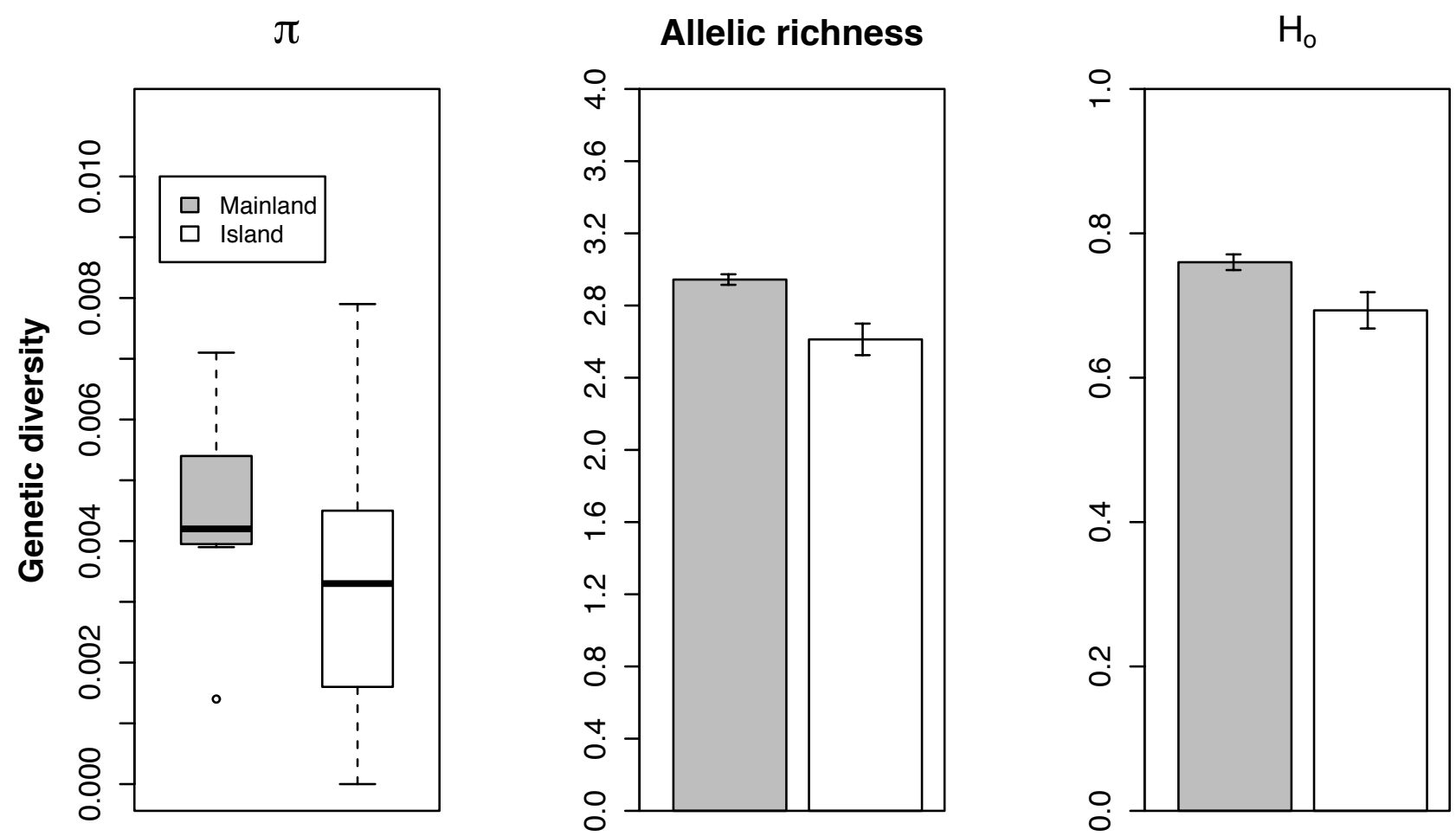

Figure 2. Genetic diversity of nine island and eleven mainland breeding locations of Kentish plovers. There was no significant difference in mitochondrial sequence diversity $\pi$, but mainland breeding locations harbored higher nuclear genetic diversity (allelic richness and observed heterozygosity Ho) than island breeding locations based on 21 autosomal microsatellite markers. Median given for $\pi$, mean \pm standard error given for allelic richness and $\mathrm{H}_{\mathrm{o}}$. 


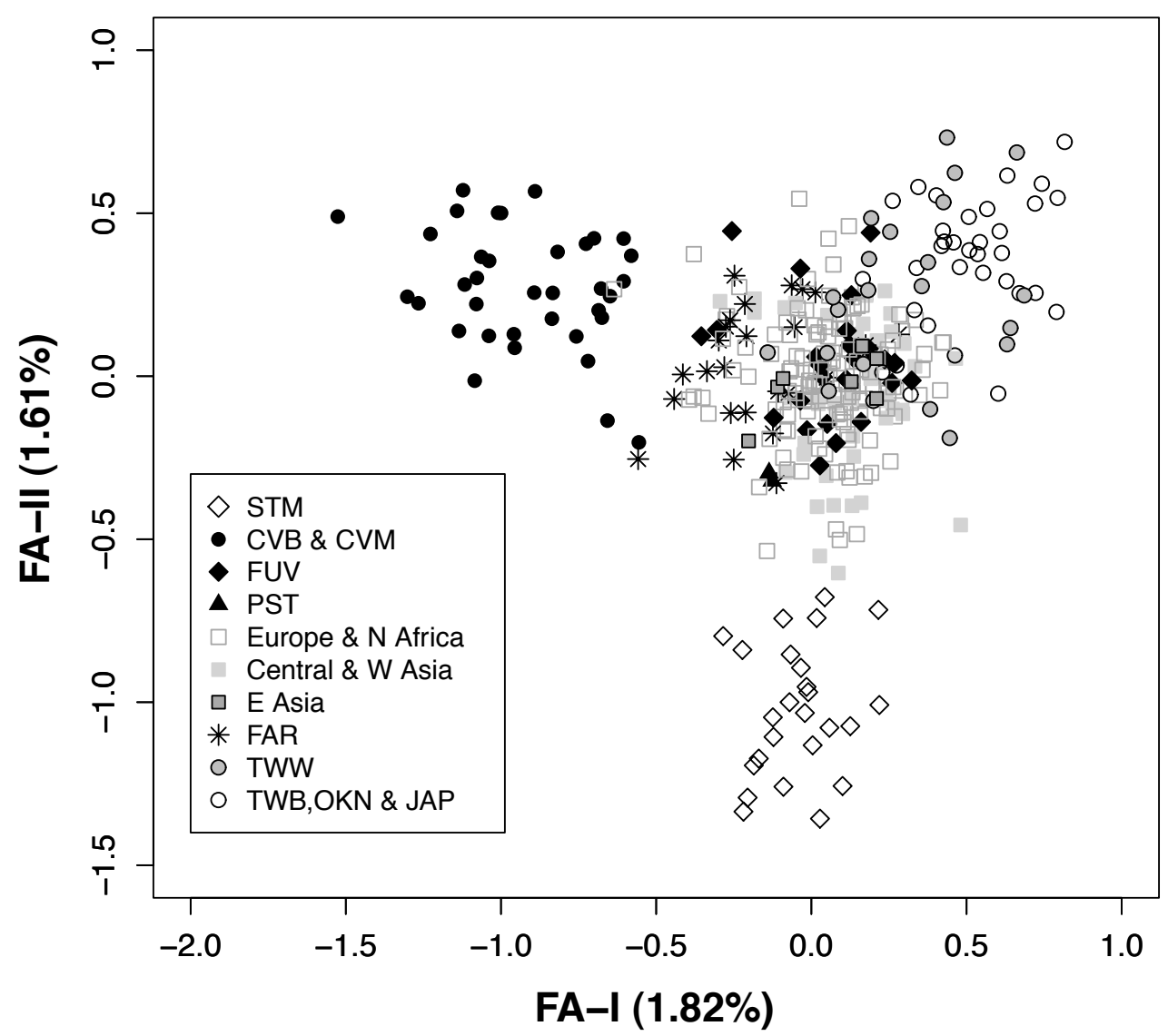

899 Figure 3. Genetic differentiation of Kentish plover populations visualized with a Factorial Correspondence Analysis. Island populations are presented with 900 open or filled black symbols. Gray squares refer to plovers sampled during the breeding season at eleven mainland sites. Europe and North Africa includes 


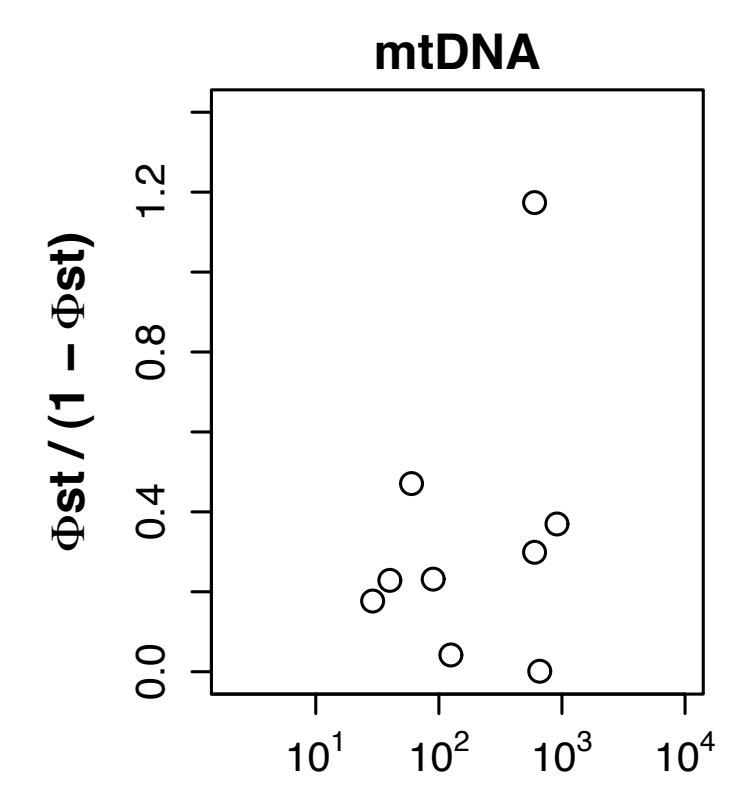

904 from XIN and $\mathrm{BOH}$.

03

samples from SAM, DON, FDP, GHR, BLK and KUJ, Central and W Asia includes samples from TUZ, ALW and ELT, and Eastern Asia includes samples
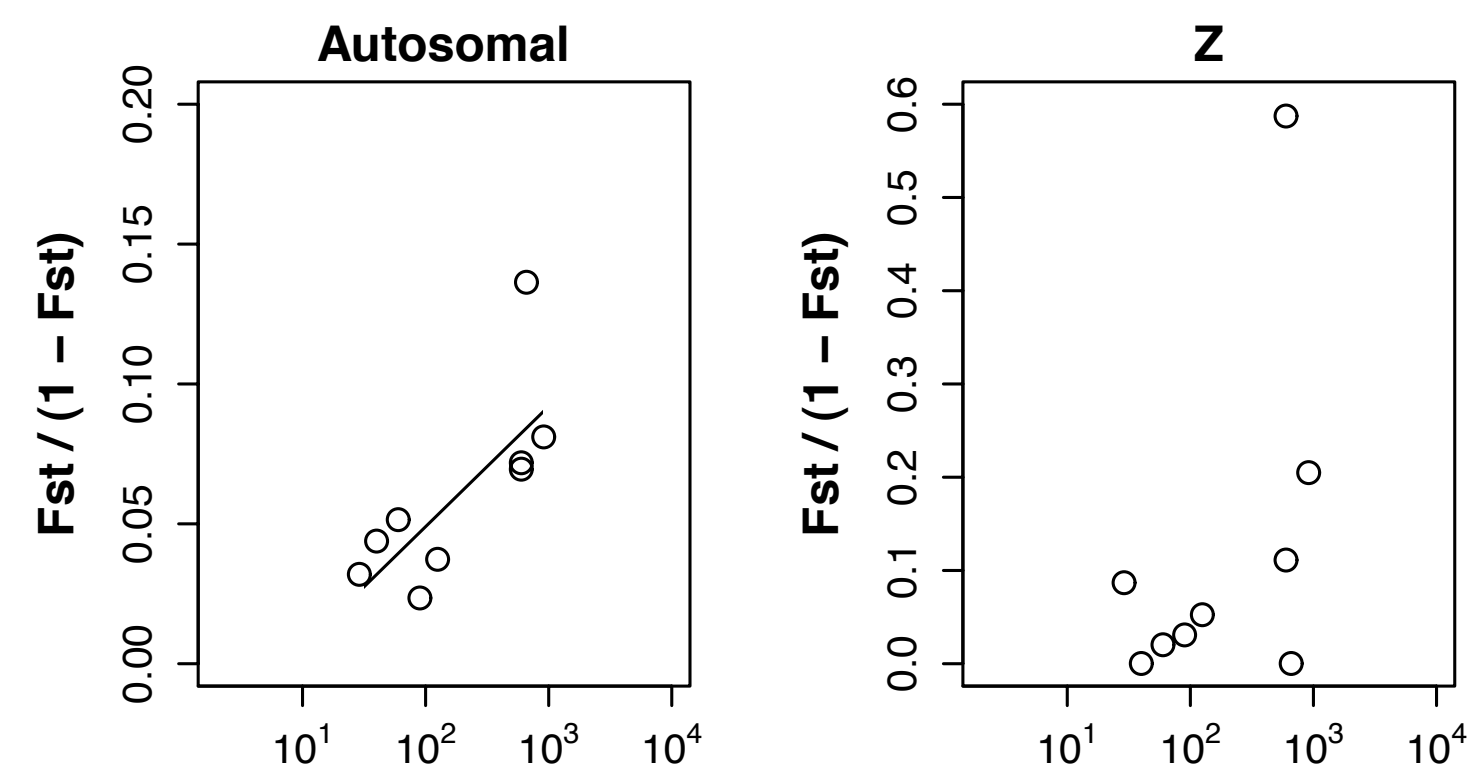

\section{Ocean Distance in km}

Figure 4. Relationship between genetic differentiation and distance over open ocean of nine island locations vs the mainland for mitochondrial DNA, autosomal microsatellites and a $\mathrm{Z}$ chromosomal microsatellite marker. Only autosomal microsatellites showed a significant linear relationship with distance. 


\section{Supporting Information}

3 Table S1. Pairwise $F_{\mathrm{ST}}$ (above diagonal) and $R_{\mathrm{ST}}$ values (below diagonal) for 20 breeding locations and one wintering location of Kentish plover 4 based on 21 autosomal microsatellites. Island breeding populations are marked by an asterisk. Negative values represent computation 5 idiosyncrasies and are effectively zero. We tested for significance using 1000 random permutations. Significant values at $P<0.01$ and $q<0.01$

6 are presented in bold; remaining values are all nonsignificant.

\begin{tabular}{|c|c|c|c|c|c|c|c|c|c|c|c|c|c|c|c|c|c|c|c|c|c|}
\hline Site & STM* & CVB* & CVM* & FUV* & PST* $^{*}$ & SAM & GHR & DON & FDP & BLK & KUJ & TUZ & FAR* & ELT & ALW & XIN & $\mathrm{BOH}$ & TWB* & TWW & OKN* & JAP* \\
\hline STM $^{*}$ & - & 0.16 & 0.17 & 0.10 & 0.18 & 0.08 & 0.11 & 0.08 & 0.09 & 0.11 & 0.09 & 0.08 & 0.13 & 0.09 & 0.08 & 0.07 & 0.11 & 0.13 & 0.11 & 0.17 & 0.15 \\
\hline $\mathrm{CVB}^{*}$ & 0.26 & - & 0.01 & 0.08 & 0.23 & 0.07 & 0.10 & 0.07 & 0.07 & 0.07 & 0.07 & 0.06 & 0.08 & 0.08 & 0.07 & 0.07 & 0.09 & 0.12 & 0.08 & 0.13 & 0.12 \\
\hline CVM* $^{*}$ & 0.22 & 0.02 & - & 0.08 & 0.24 & 0.08 & 0.11 & 0.07 & 0.07 & 0.06 & 0.08 & 0.07 & 0.07 & 0.10 & 0.07 & 0.09 & 0.08 & 0.11 & 0.08 & 0.14 & 0.13 \\
\hline $\mathrm{PST}^{*}$ & 0.34 & 0.41 & 0.47 & 0.31 & - & 0.11 & 0.17 & 0.13 & 0.14 & 0.15 & 0.10 & 0.11 & 0.13 & 0.11 & 0.12 & 0.12 & 0.16 & 0.18 & 0.16 & 0.26 & 0.21 \\
\hline SAM & 0.04 & 0.09 & 0.13 & 0.03 & 0.20 & - & 0.02 & 0 & 0.01 & 0.02 & 0 & 0.01 & 0.04 & 0 & 0.01 & -0.01 & 0.02 & 0.04 & 0.02 & 0.07 & 0.07 \\
\hline GHR & 0.09 & 0.16 & 0.22 & 0.10 & 0.18 & 0.03 & - & 0.02 & 0.03 & 0.02 & 0.02 & 0.02 & 0.06 & 0.03 & 0.02 & 0.03 & 0.02 & 0.06 & 0.04 & 0.07 & 0.06 \\
\hline FDP & 0.10 & 0.05 & 0.11 & 0.04 & 0.17 & 0.01 & 0.03 & 0.01 & - & 0.01 & 0.01 & 0.01 & 0.03 & -0.01 & 0 & -0.01 & 0.02 & 0.05 & 0.02 & 0.05 & 0.05 \\
\hline BLK & 0.15 & 0.13 & 0.16 & 0.04 & 0.20 & 0.04 & 0.02 & 0.01 & 0.03 & - & 0.01 & 0.01 & 0.03 & 0 & 0.01 & 0.01 & 0.01 & 0.04 & 0.02 & 0.05 & 0.05 \\
\hline KUJ & 0.11 & 0.09 & 0.17 & 0.08 & 0.12 & 0.02 & -0.01 & 0.02 & 0 & 0.02 & - & 0 & 0.03 & 0 & 0 & -0.01 & 0 & 0.03 & 0.02 & 0.05 & 0.05 \\
\hline TUZ & 0.08 & 0.07 & 0.13 & 0.06 & 0.17 & 0.01 & 0 & 0 & 0 & 0.03 & 0 & - & 0.04 & 0 & 0.01 & -0.01 & 0.01 & 0.03 & 0.02 & 0.04 & 0.04 \\
\hline FAR* & 0.13 & 0.03 & 0.06 & 0.03 & 0.20 & 0.02 & 0.04 & 0.03 & 0.01 & 0.02 & 0.02 & 0.02 & - & 0.02 & 0.03 & 0.03 & 0.05 & 0.07 & 0.04 & 0.06 & 0.08 \\
\hline ELT & 0.12 & 0.07 & 0.14 & 0.06 & 0.15 & 0.02 & -0.01 & 0 & -0.01 & 0.01 & -0.02 & 0 & 0 & - & 0 & -0.01 & 0.01 & 0.03 & 0.02 & 0.05 & 0.05 \\
\hline ALW & 0.09 & 0.06 & 0.10 & 0.03 & 0.22 & 0.01 & 0.02 & -0.01 & 0 & 0.01 & 0.01 & 0 & 0.01 & 0 & - & -0.01 & 0.03 & 0.04 & 0.02 & 0.05 & 0.05 \\
\hline XIN & 0.06 & 0.14 & 0.20 & 0.06 & 0.21 & -0.01 & -0.05 & -0.03 & 0 & 0.04 & -0.01 & -0.01 & 0.03 & -0.01 & 0 & - & 0 & 0.03 & 0.01 & 0.08 & 0.03 \\
\hline TWB* & 0.13 & 0.12 & 0.14 & 0.05 & 0.29 & 0.05 & 0.04 & 0.03 & 0.04 & 0.07 & 0.06 & 0.05 & 0.05 & 0.05 & 0.02 & 0.02 & 0.01 & - & 0.01 & 0.06 & 0.05 \\
\hline TWW & 0.15 & 0.08 & 0.10 & 0.04 & 0.31 & 0.04 & 0.05 & 0.03 & 0.02 & 0.03 & 0.05 & 0.04 & 0.02 & 0.03 & 0 & 0.02 & -0.01 & 0 & - & 0.03 & 0.02 \\
\hline OKN* & 0.15 & 0.22 & 0.25 & 0.07 & 0.25 & 0.07 & 0.06 & 0.07 & 0.07 & 0.08 & 0.04 & 0.09 & 0.06 & 0.05 & 0.06 & 0.06 & 0.04 & 0.04 & 0.06 & - & 0.03 \\
\hline JAP* & 0.10 & 0.20 & 0.25 & 0.10 & 0.21 & 0.08 & 0 & 0.02 & 0.06 & 0.05 & 0.05 & 0.04 & 0.10 & 0.01 & 0.04 & 0.01 & -0.01 & 0.05 & 0.07 & 0.02 & - \\
\hline
\end{tabular}


8 Table S2. Pairwise $\Phi_{\mathrm{ST}}$ values based on a mitochondrial marker (above diagonal) and pairwise $F_{S T}$ values based on a Z-linked microsatellite 9 marker (below diagonal, calculated with males only) for 20 breeding locations and one wintering location of Kentish plover. Island breeding 10 populations are marked by an asterisk. Negative values represent computation idiosyncrasies and are effectively zero. We tested for significance 11 using 1000 random permutations. Significant values at $P<0.01$ and $q<0.01$ are presented in bold; remaining values are all nonsignificant.

\begin{tabular}{|c|c|c|c|c|c|c|c|c|c|c|c|c|c|c|c|c|c|c|c|c|c|}
\hline Site & STM* & CVB* & CVM* & FUV* & PST* $^{*}$ & SAM & GHR & DON & FDP & BLK & KUJ & TUZ & FAR* & ELT & ALW & XIN & $\mathrm{BOH}$ & TWB* & TWW & $\mathrm{OKN}^{*}$ & JAP* \\
\hline STM* & - & 0.92 & 0.45 & 0.27 & 0.94 & 0.37 & 0.49 & 0.41 & 0.37 & 0.58 & 0.29 & 0.33 & 0.30 & 0.42 & 0.54 & 0.49 & 0.86 & 0.30 & 0.56 & 0.65 & 0.52 \\
\hline $\mathrm{CVB}^{*}$ & 0.47 & - & 0.32 & 0.62 & 0.90 & 0.60 & 0.62 & 0.61 & 0.59 & 0.65 & 0.45 & 0.58 & 0.53 & 0.44 & 0.62 & 0.53 & 0.84 & 0.41 & 0.60 & 0.70 & 0.61 \\
\hline $\mathrm{CVM}^{*}$ & 0.29 & 0.16 & - & 0.32 & 0.32 & 0.23 & 0.25 & 0.25 & 0.27 & 0.30 & 0.17 & 0.23 & 0.22 & 0.13 & 0.22 & 0.23 & 0.39 & 0.18 & 0.29 & 0.33 & 0.30 \\
\hline FUV* & 0.13 & 0.51 & 0.24 & - & 0.44 & 0.17 & 0.23 & 0.20 & 0.19 & 0.28 & 0.16 & 0.16 & 0.21 & 0.26 & 0.34 & 0.24 & 0.38 & 0.15 & 0.27 & 0.30 & 0.26 \\
\hline $\mathrm{PST}^{*}$ & -0.09 & 0.57 & 0.06 & -0.36 & - & 0.02 & -0.10 & -0.06 & 0.02 & -0.17 & -0.06 & 0.03 & 0.32 & -0.13 & -0.09 & -0.18 & -0.02 & -0.08 & -0.17 & 0.71 & 0.34 \\
\hline SAM & 0.20 & 0.46 & 0.10 & 0.03 & -0.27 & - & -0.03 & -0.05 & -0.02 & 0.00 & -0.02 & -0.04 & 0.13 & 0.05 & 0.10 & -0.02 & 0.04 & -0.01 & 0.01 & 0.34 & 0.18 \\
\hline GHR & 0.22 & 0.30 & -0.02 & 0.14 & -0.13 & 0.01 & - & -0.04 & -0.01 & -0.03 & -0.02 & -0.02 & 0.14 & 0.04 & 0.07 & -0.06 & 0.01 & -0.01 & -0.01 & 0.37 & 0.20 \\
\hline DON & 0.06 & 0.39 & 0.15 & -0.01 & -0.32 & 0.03 & 0.07 & - & -0.03 & -0.04 & -0.01 & -0.02 & 0.14 & 0.05 & 0.09 & -0.02 & 0.00 & 0.01 & 0.00 & 0.36 & 0.20 \\
\hline FDP & 0.19 & 0.44 & 0.11 & 0.06 & -0.21 & -0.03 & 0.01 & 0.06 & - & -0.02 & 0.01 & -0.01 & 0.15 & 0.07 & 0.14 & 0.00 & 0.06 & 0.00 & 0.03 & 0.33 & 0.18 \\
\hline BLK & 0.15 & 0.30 & 0.06 & 0.10 & -0.18 & 0.05 & -0.01 & 0.03 & 0.02 & - & 0.01 & 0.02 & 0.22 & 0.03 & 0.08 & -0.02 & -0.03 & 0.03 & -0.02 & 0.43 & 0.24 \\
\hline KUJ & 0.16 & 0.48 & 0.12 & -0.02 & -0.35 & -0.07 & 0.01 & -0.01 & -0.04 & 0.03 & - & -0.01 & 0.09 & 0.04 & 0.09 & -0.01 & 0.04 & 0.00 & 0.01 & 0.24 & 0.12 \\
\hline TUZ & 0.16 & 0.44 & 0.14 & 0 & -0.31 & -0.03 & 0.04 & 0.01 & -0.01 & 0.03 & -0.06 & - & 0.12 & 0.06 & 0.11 & 0.01 & 0.05 & 0.01 & 0.02 & 0.30 & 0.16 \\
\hline FAR* & 0.23 & 0.20 & 0.01 & 0.20 & -0.03 & 0.10 & -0.01 & 0.10 & 0.07 & -0.01 & 0.10 & 0.11 & - & 0.21 & 0.28 & 0.18 & 0.30 & 0.11 & 0.20 & 0.29 & 0.23 \\
\hline ELT & 0.24 & 0.63 & 0.18 & 0.05 & -0.23 & -0.06 & 0.04 & 0.08 & -0.05 & 0.09 & -0.07 & -0.03 & 0.14 & - & 0.02 & 0.02 & 0.04 & 0.06 & 0.05 & 0.30 & 0.20 \\
\hline ALW & 0.12 & 0.33 & 0.08 & 0.02 & -0.27 & 0 & 0.01 & -0.01 & 0 & -0.04 & -0.02 & -0.02 & 0.04 & 0.04 & - & 0.05 & 0.11 & 0.12 & 0.09 & 0.42 & 0.29 \\
\hline XIN & 0.35 & 0.68 & 0.18 & 0.23 & 0.09 & 0.05 & 0.02 & 0.22 & 0.01 & 0.13 & 0.07 & 0.10 & 0.14 & -0.02 & 0.14 & - & -0.04 & -0.03 & -0.02 & 0.29 & 0.18 \\
\hline $\mathrm{BOH}$ & 0.15 & 0.47 & 0.09 & 0.04 & -0.30 & -0.04 & -0.06 & 0 & -0.06 & -0.03 & -0.05 & -0.03 & -0.01 & -0.04 & -0.02 & -0.02 & - & 0.02 & -0.06 & 0.66 & 0.36 \\
\hline TWB* & 0.11 & 0.49 & 0.24 & -0.03 & -0.34 & 0.05 & 0.14 & -0.02 & 0.08 & 0.10 & 0 & 0.02 & 0.18 & 0.08 & 0.03 & 0.24 & 0.03 & - & -0.02 & 0.11 & 0.06 \\
\hline TWW & 0.14 & 0.43 & 0.15 & 0.02 & -0.28 & 0 & 0.04 & 0 & 0 & 0.04 & -0.02 & 0 & 0.07 & 0 & 0.01 & 0.10 & -0.09 & 0.01 & - & 0.30 & 0.07 \\
\hline OKN* & 0.02 & 0.52 & 0.21 & -0.05 & -0.43 & 0.05 & 0.09 & -0.12 & 0.06 & 0 & 0 & 0 & 0.06 & 0.13 & -0.04 & 0.31 & -0.09 & -0.10 & -0.08 & - & -0.05 \\
\hline JAP* & 0.08 & 0.45 & 0.13 & 0.04 & -0.33 & 0.06 & -0.02 & -0.03 & 0.01 & -0.15 & 0.02 & 0 & -0.01 & 0.11 & -0.08 & 0.16 & -0.13 & 0.03 & -0.02 & -0.13 & - \\
\hline
\end{tabular}




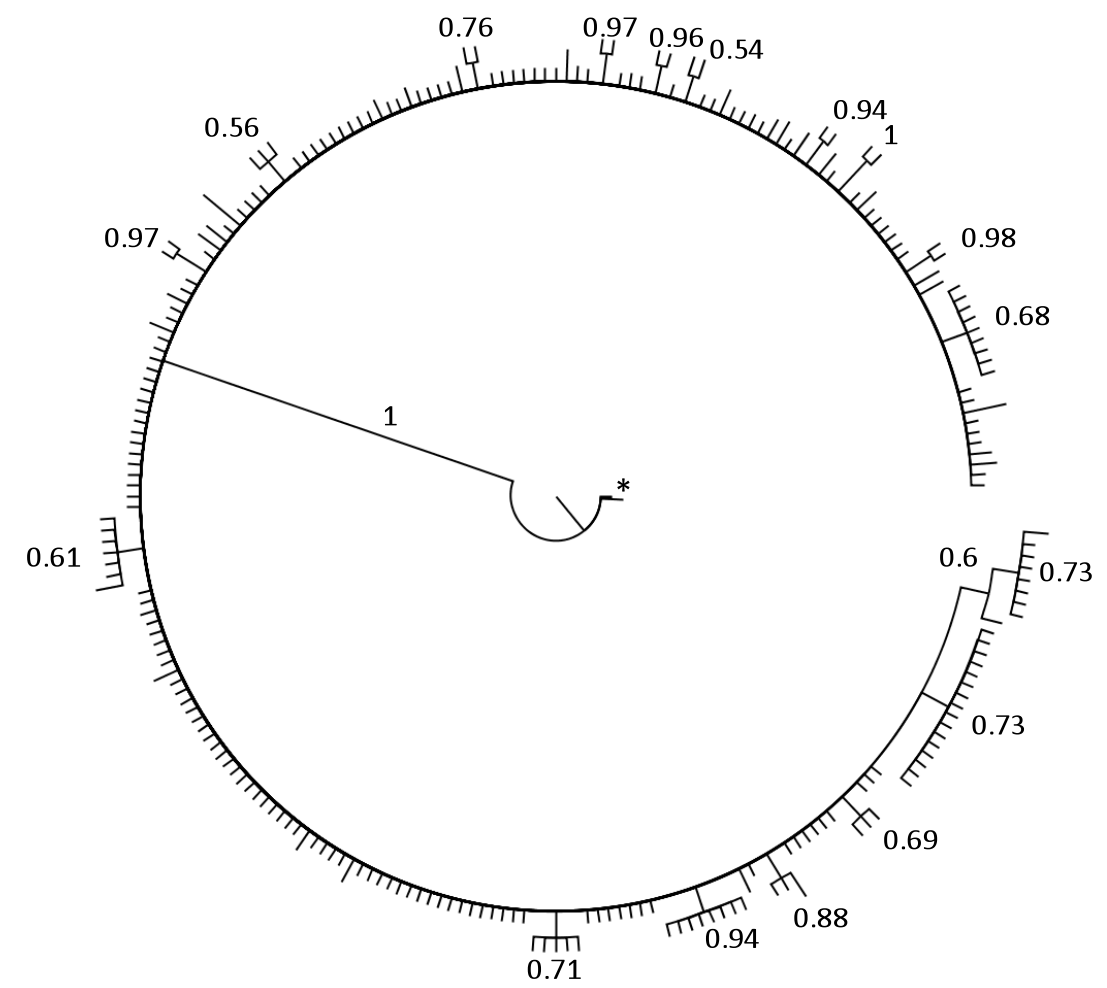

Figure S1. Bayesian phylogeny based on a 427 bp mitochondrial DNA control region fragment of 245 Kentish plovers with three snowy plovers as outgroup (indicated by asterisk). Only five nodes are well supported $(>0.95)$ and the topology is poorly associated with geographic distribution of the haplotypes. Two alternative topologies (not shown) constrained by geographic origin of the samples received little support. 